\title{
THESIS
}

\section{LIPOSOMAL ENCAPSULATED ALPHA-LIPOIC ACID, BENFOTIAMINE AND CURCUMIN PREVENT OVERFEEDING MEDIATED INCREASES IN WAIST CIRCUMFERENCE}

\author{
Submitted by \\ Nathan Carlisle Grimm \\ Department of Health and Exercise Science
}

In partial fulfillment of the requirements

For the Degree of Master of Science

Colorado State University

Fort Collins, Colorado

Spring 2017

Master's Committee:

Advisor: Christopher Bell

Gregory Dooley

Matthew Hickey 
Copyright by Nathan Grimm 2017

All Rights Reserved 


\section{ABSTRACT}

\section{LIPOSOMAL ENCAPSULATED ALPHA-LIPOIC ACID, BENFOTIAMINE AND}

CURCUMIN PREVENT OVERFEEDING MEDIATED INCREASES IN WAIST CIRCUMFERENCE

INTRODUCTION: To determine if liposomal (L) encapsulated alpha-lipoic acid $(0.5 \mathrm{~g})$, benfotiamine $(0.5 \mathrm{~g})$ and curcumin $(2.0 \mathrm{~g})(\mathrm{ABC})$ would prevent the unfavorable metabolic consequences of sedentary high-fat overfeeding in healthy young adults.

METHODS: 29 young (18-30 years), healthy, physically active men and women were randomly assigned to ingest placebo $(n=9), A B C(n=10)$, or L-ABC $(n=10)$ twice daily for 28 days. Between days 22 and 28 all participants abstained from their normal regular exercise and consumed a high calorie, high fat diet.

RESULTS: On Day 29, circulating alpha lipoic acid was greater $(\mathrm{p}<0.01)$ in L-ABC (412 $\pm 73 \mathrm{ng} / \mathrm{mL})$ compared with ABC $(154 \pm 33 \mathrm{ng} / \mathrm{mL})$. During the sedentary high fat overfeeding, dietary intake was not different ( $p>0.6)$ between groups $(\sim 3,400 \mathrm{kcal} / \mathrm{day} ; \sim 50 \%$ from fat). Sedentary high fat overfeeding increased $(\mathrm{p}<0.05)$ waist circumference in the placebo $(+2.7 \pm 2.7 \mathrm{~cm})$ and $\mathrm{ABC}(+3.3 \pm 2.0)$ groups but not the L-ABC group $(+0.7 \pm 2.7)$. The magnitudes of increase $(\mathrm{p}<0.05)$ in body mass $(1.7 \pm 0.3 \mathrm{~kg})$, fat mass $(0.7 \pm 0.2 \mathrm{~kg})$, and blood pressure $(3 \pm 1 \mathrm{mmHg})$ and decrease $(\mathrm{p}<0.05)$ in insulin sensitivity (Matsuda Index: $-2.9 \pm 0.9)$ after overfeeding were not different between groups (all $\mathrm{p}>0.50$ ).

DISCUSSION: Liposomal encapsulated alpha-lipoic acid, benfotiamine and curcumin: 1) promoted alpha-lipoic acid bioavailability; and, 2) prevented sedentary high-fat overfeeding mediated increases in waist circumference in usually active healthy young adults. These data 
may have important public health implications for periods of inactive overconsumption such as during seasonal celebrations. 


\section{ACKNOWLEDGEMENTS}

I would like to start by thanking all the participants who volunteered for the study. A special thanks to Empirical Labs in Fort Collins, $\mathrm{CO}$ for providing the supplements used in the study. Thank you to Brittney Sly for handling dietary instruction for the study. Thank you to Drs. Kim Cox-York and Tiffany Weir for collaborating on this project from the Department of Food Science and Human Nutrition.

I would like to give a special thanks to my mentor, Dr. Christopher Bell, for his support throughout this process. Your mentorship will influence me long past my time at Colorado State. A special thank you to my colleagues past and present from the Integrative Biology Laboratory. Not only to thank you for helping with this project but for your friendship and support in and out of the laboratory. A special thanks to my committee members, Dr. Dooley for all your expertise in analytical chemistry and academic/career advice, and Dr. Hickey for your mentorship in and out of the classroom throughout my time at Colorado State.

Finally, I would like to thank my family and friends for the continued support without whom I would not be where I am today. A special thanks to my parents Kenny and Heidi, my Uncle Eric, my Grandfather Ron, my Grandmother Ruth and for your continued support throughout my academic career. 


\section{TABLE OF CONTENTS}

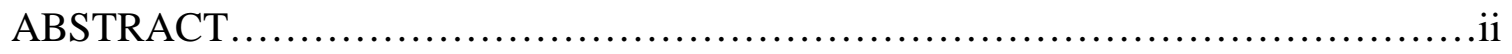

ACKNOWLEDGEMENTS..................................................iv

CHAPTER I....................................................................

LITERATURE REVIEW ..............................................

STATEMENT OF THE PROBLEM.....................................

HYPOTHESIS ..................................................... 10

SPECIFIC AIMS .................................................. 10

CHAPTER II............................................................. 11

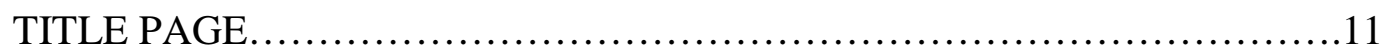

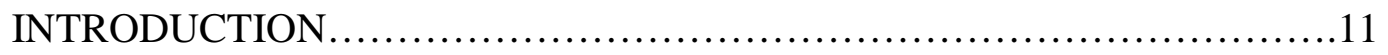

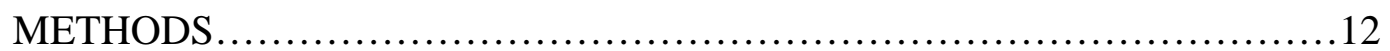

RESULTS...................................................... 19

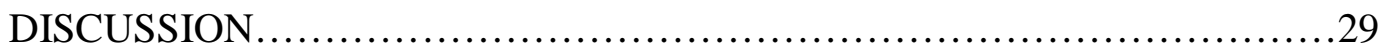

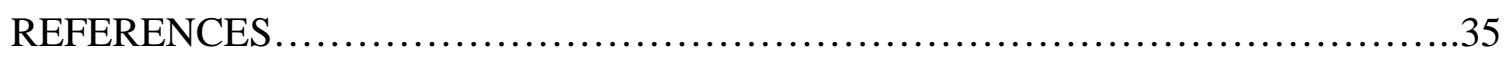

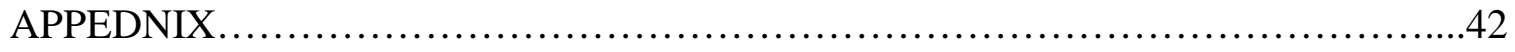

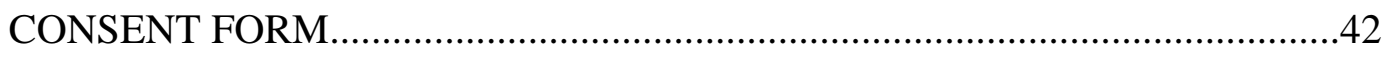




\section{CHAPTER I}

\section{LITERATURE REVIEW}

Diabetes is a disease plaguing over 422 million adults worldwide ${ }^{1}$. There is currently no known prevention for type 1 diabetes. Type 2 diabetes (T2D) is characterized by insulin resistance and is often diagnosed with multiple comorbidities such as obesity, dyslipidemia, and

cardiovascular disease ${ }^{2}$. This study will focus on the prevention of T2D. T2D has been closely associated with obesity and sedentary lifestyles. Physical activity and dietary interventions have been successful to reduce body weight and help prevent T2D ${ }^{1}$. Unfortunately, interventions for body weight reduction do not have lasting compliance ${ }^{3}$. This non-compliance has led to pharmacological interventions such as metformin and acarbose ${ }^{1}$.

Pharmacological interventions have a few limitations including, compliance, the need for life-long use, and adverse side effects such as dizziness, severe drowsiness, muscle pain, etc. ${ }^{4}$. One alternative prevention and treatment method may be nutraceuticals, a food or part of food that has beneficial medicinal activity beyond its nutritional value. Nutraceuticals often have less unwanted side effects compared to drugs treating the same cardio-metabolic problems ${ }^{5}$. Among the plethora of dietary supplements purported to have beneficial effects, several have fared well following scientific scrutiny. These include Alpha-Lipoic Acid (ALA), Benfotiamine (BEN), and Curcumin (CUR).

CUR is the active ingredient of the spice turmeric. ALA is a signaling molecule within human mitochondria. BEN is a bioactive derivative of thiamine, the water soluble vitamin B1. All three of these individual supplements are reported to have anti-inflammatory and antioxidant properties ${ }^{6-10}$. 
In studies of cell culture and laboratory mice, nutraceutical administration has yielded some beneficial responses. In contrast, the data from human trials are less convincing, in part due to limited bioavailability following ingestion. Our study will assess the efficacy of combining these three nutraceuticals and address the problems associated with bioavailability following oral consumption. Before exploring the benefits of these supplements, the physiology of obesity and diabetes will be addressed.

Hyperglycemia, Reactive Oxygen Species and Inflammation

Chronically high blood glucose, a hallmark of diabetes, can be associated with increased reactive oxygen species (ROS) formation, increased inflammation, elevated circulating triglycerides, excess fat storage, and insulin resistance ${ }^{11-14}$. Excessive ROS generation and increased inflammation can also lead to development of atherosclerosis and cardiovascular disease, a comorbidity responsible for the majority of deaths in individuals with diabetes ${ }^{15}$. Hyperglycemia induced oxidative stress leads to pathophysiological changes such as the increased inflammation of various metabolic tissues such as fat, skeletal muscle and the liver ${ }^{16-}$ ${ }^{19}$. Conversely, inflammation can induce hyperglycemia and impaired glucose tolerance ${ }^{17}$. This means hyperglycemia can induce inflammation and vice versa, further complicating the treatment approach.

Excess fat storage can lead to ROS formation from adipocytes and is associated with increased macrophage infiltration of those adipocytes ${ }^{20}$. This macrophage infiltration is a common characteristic of obesity ${ }^{13,14}$ and can lead to the activation of inflammatory pathways such as c-Jun NH2-terminal kinase (JNK) and nuclear factor- $\mathrm{KB}(\mathrm{NF}-\kappa \mathrm{B}){ }^{21}$. Both pathways can interfere with IRS-1 phosphorylation, halting the insulin signaling cascade and resulting in decreased glucose transporter type 4 (GLUT4) translocation. Interfering with IRS-1 signaling 
can lead to increased insulin resistance in in multiple metabolic tissues such as skeletal muscle, liver and adipose tissue. There is evidence that inflammation from adipocytes can lead to decreased insulin sensitivity in skeletal muscle and liver tissues ${ }^{22}$.

$\mathrm{NF}-\kappa \mathrm{B}$ is a transcription factor that produces gene products such as tumor necrosis factor$\alpha(\mathrm{TNF} \alpha)$ and interlukin-6 (IL-6). Short term presence of these cytokines can be beneficial in muscle tissue recovery, however chronic elevation systemically, may contribute to the development of insulin resistance and other metabolic dysfunctions ${ }^{13,23}$. Fortunately, this can be reversed; for example, an eight week weight loss intervention in obese adults with persistent inflammation led to decreased circulating TNF $\alpha$ and IL-6 levels ${ }^{24}$. Taken together these findings associate the hallmark hyperglycemia seen in diabetes, and in some cases of obesity, to ROS generation with inflammation of various metabolic tissues such adipocytes, skeletal muscle and the liver.

Given the poor compliance of participants using dietary and exercise interventions, alternative options need to be explored. Pharmaceuticals can have unwanted side effects and often require lifetime use. Nutraceuticals offer less unwanted side effects and can achieve the same outcome as first-line drugs with lower costs of production ${ }^{25}$. Mechanistically, nutraceuticals such as dietary polyphenols have gained much interest over the past decade. Specifically, polyphenols with anti-oxidant and anti-inflammatory properties can be a promising intervention for individuals diagnosed with prediabetes and T2D ${ }^{26}$; one such molecule is curcumin. 


\section{Curcumin}

Curcumin (Diferuloylmethane) is a polyphenolic compound found in the Indian spice turmeric (Curcuma longa). As of the last quarter century, curcumin has been researched for the prevention and treatment of many human diseases ${ }^{27,28}$, including diabetes mellitus ${ }^{29,30}$, Alzheimer's disease ${ }^{31}$, cardiovascular disease ${ }^{32,33}$, and cancer ${ }^{28}$. Relevant to the pathology of diabetes, CUR is an antioxidant ${ }^{32,34,35}$, a JNK pathway inhibitor ${ }^{36}$, and an NF- $\kappa \mathrm{B}$ pathway inhibitor $^{37}$. As mentioned earlier, inhibition of these pathways leads to decreased macrophage infiltration of adipocytes, decreased pro-inflammatory cytokines such as TNF $\alpha$ and IL-6, and increased anti-inflammatory adipokines, including adiponectin. Therefore, this makes CUR a promising supplement for the treatment and prevention of inflammation induced insulin resistance $^{29}$.

In research settings, high fat diets are often used to impair the metabolic systems of mice, and CUR has been shown to protect mice from high fat diet-induced insulin resistance. CUR provided protection by decreasing liver lipogenesis via lipogenic gene suppression and also by decreasing inflammation in adipose tissue ${ }^{30,38}$. Furthermore, these metabolic improvements from CUR could be related to decreases in macrophage infiltration, and TNF $\alpha$ and IL-6 in adipose tissues ${ }^{38}$. These reports show the efficacy of curcumin in preventing inflammation in the face of a dietary insults such as high fat diets.

Aside from the anti-inflammatory mediated improvements in lipid metabolism, CUR has also been seen to activate adenosine monophosphate-activated protein kinase (AMPK) in skeletal muscle and liver ${ }^{39,40}$. AMPK acts as a fuel regulator in the cell ${ }^{41}$. In skeletal muscle, AMPK can increase glucose uptake and fatty acid oxidation ${ }^{42,43}$. CUR may help reduce insulin resistance via alterations in lipid metabolism either from AMPK or anti-inflammatory mechanisms. 
The benefits of CUR are not limited to animals. For example, in a previous study of humans with prediabetes ( $\mathrm{n}=240$ ), 9 months of CUR extract supplementation decreased body weight, fasting blood glucose, HbA1c , insulin, and values for Homeostatic Model Assessment of Insulin Resistance (HOMA-IR) ${ }^{29}$. CUR supplementation also increased circulating adiponectin, and improved beta cell function (HOMA- $\beta)^{29}$. At the end of the study, $16.4 \%$ of subjects receiving placebo were diagnosed with $\mathrm{T} 2 \mathrm{D}$ whereas none of the CUR treated group developed T2D.

\section{Bioavailability}

While in theory the use of CUR shows promise as a preventative treatment, in reality the beneficial effects of CUR may be limited by low oral bioavailability. This is due to CUR having poor solubility in the blood stream, slow absorption rates from the gut, as well as a rapid metabolism to inactive products ${ }^{44}$. Despite high doses ranging from 8-12 grams of CUR per day, active curcuminoids such as CUR, dimethoxycurcumin, and bisdemethoxycurcumin could not be detected in circulating plasma of humans $(<50 \mathrm{ng} / \mathrm{ml}){ }^{45,46}$. It is likely these active curcuminoids are rapidly breaking down to inactive metabolites such as glucuronides and sulfates ${ }^{46}$.

\section{Alpha-Lipoic Acid}

Another nutraceutical for the treatment and prevention of diabetes is ALA (1,2dithiolane-3-pentanoic acid). ALA is made endogenously from octanoic acid in the mitochondria. ALA plays a role in mitochondrial metabolism as it is a necessary cofactor for $\alpha$ ketoacid dehydrogenases ${ }^{9}$. Exogenously, ALA is available in small amounts from fruits and vegetables, as well as from some organ meats such as heart, kidney, liver and in recent years it has been included as an ingredient in many multivitamin mixtures ${ }^{9}$. 
Like CUR, ALA supplementation may benefit many disease populations. There is potential for therapeutic use in diseases such as cancer ${ }^{47}$, cardiovascular disease ${ }^{48}$, Alzheimer's disease $^{49}$, and diabetic polyneuropathies ${ }^{9}$. ALA is posited to exert benefits through ROS removal, chelation of metal ions, and reducing the oxidized forms of other antioxidants ${ }^{8}$. In addition, ALA can also aid in weight loss by suppressing the activity of AMPK within the hypothalamus and consequently will reduce food intake in rats ${ }^{50}$. In humans, $1800 \mathrm{mg}$ per day ALA supplementation over 20 weeks lowered body weight compared to placebo ${ }^{51}$.

In rats with hyperglycemia induced hypertension, ALA prevented the rise of systolic blood pressure compared to the control group. ${ }^{52}$. Additionally, HOMA-IR was significantly lower in the ALA treated group. The researchers attributed some of these improvements to attenuated superoxide production (O2-), and maintenance of antioxidative proteins.

ALA has also been reported to reduce circulating free fatty acids and triglycerides in humans with impaired glucose tolerance ${ }^{53}$. On a transcriptional level, high fat diet fed mice begin to lose the capacity to tolerate oxidative stress due to decreases in ROS scavenger proteins such as superoxide dismutase, metallothioneins, and thioredoxins. ALA supplementation partially prevented the alterations to these ROS scavengers in high fat diet fed mice ${ }^{54}$. ALA added to normal chow improved hypertriglyceridemia in rats by increasing triacylglycerol clearance and downregulating liver triacylglycerol secretion ${ }^{55}$. These findings imply better lipid metabolism in the face of a high fat diet.

\section{Bioavailability}

ALA has one chiral center and can be found as R-(+) and S-(-) enantiomers; only the R$(+)$ enantiomer is bioactive. When given a racemic mixture of ALA, plasma concentrations of the 
R-(+) enantiomer were $40-50 \%$ higher than the S-(-) ${ }^{56}$. Cellular absorption of ALA is facilitated by two primary proteins, monocarboxylate transporter (MCT) and sodium dependent multivitamin transporter (SMVT) ${ }^{47}$. Furthermore, SMVT has preferential uptake of R-(+)-ALA configuration over S-(-)-ALA ${ }^{57}$. ALA undergoes quick metabolism via first pass through the liver, and $\beta$-oxidation of the carboxylic acid side chain degrades ALA into over 10 different metabolites ${ }^{58}$. This rapid degradation can impede the efficacy of ALA as an antioxidant and anti-inflammatory.

\section{Benfotiamine}

Benfotiamine $(\mathrm{BEN})$ is a lipophilic derivative of thiamine, the water soluble vitamin $\mathrm{B} 1$. The active molecule of thiamine is Thiamine diphosphate (TPP). Thiamine deficiency (TD) exists in many diseased populations and can lead to multiple neurological and metabolic problems. For example, TD has been associated with alcoholism, bariatric surgery, cardiac failure, renal failure and diabetes ${ }^{59}$. TD can lead to increased oxidative stress, excitotoxicity, and inflammation ${ }^{60}$. Oral administration of BEN resulted in higher plasma concentrations of thiamine than an equal dose of thiamine hydrochloride ${ }^{61}$, displaying the efficacy of BEN administration over thiamine.

\section{Thiamine and Hyperglycemia}

The role of supplementing thiamine for prevention of polyneuropathies in Alzheimer's and other diseases is well established ${ }^{59}$. Its ability to lower blood glucose is less clear. In a double blind placebo controlled experiment, high doses of thiamine (300mg /day) over 6 weeks improved glucose control and HOMA-IR compared to placebo arms ${ }^{62}$. These improvements in glucose regulation were also accompanied by lower blood pressures ${ }^{63}$. 
Thiamine supplementation attenuated high fructose diet induced insulin resistance in rats ${ }^{64}$. Daily $100 \mathrm{mg}$ doses increased serum thiamine concentrations after 6 months in adult humans with and without diabetes. The only metabolic improvements were lowered plasma triglycerides and low density lipoproteins in the patients with T2D ${ }^{65}$. One month of $150 \mathrm{mg} /$ day thiamine supplementation in patients with T2D had no effect on HbA1c, but did decrease fasting blood glucose ${ }^{66}$. Overall it is clear thiamine supplementation is beneficial for favorably modifying diabetic polyneuropathies. However, the literature is mixed on the efficacy of thiamine in glycemic control and insulin resistance.

CUR, ALA and BEN have not been supplemented in combination in a healthy human population. Our lab has administered CUR and ALA to an overweight and obese population; neither energy expenditure nor insulin sensitivity were favorably modified ${ }^{67}$. The limiting factor may be oral bioavailability. One way to solve a bioavailability problem is with liposomal encapsulation.

\section{Liposomes}

Liposomes are manufactured, microscopic hollow vesicles made primarily of phospholipids. Their discovery occurred back in 1965 when Bangham et al. moved ions across liquid crystals of lecithin and noted the similarity to cell membranes ${ }^{68}$. Researchers have utilized liposomal technology and similar methods such as micelle and nanoparticle encapsulation to administer pharmacological products for decades. These formulations are often cheap to produce, have low toxicity, and are adjustable in size ${ }^{69}$.

Advantages of using liposomal encapsulation include accelerated intestinal absorption, increased stability of encapsulated products, protection of the gut from potentially irritating 
agents, and greater bioavailability of the product ${ }^{70}$. Our laboratory observed greater circulating ascorbic acid concentrations following liposomal administration of vitamin $\mathrm{C}$ in humans ${ }^{71}$. CUR given orally in micelles had an 88 -fold increase in bioavailability compared to non-micelle administration. Additionally, phytochemicals suspected to facilitate CUR transport only resulted in an 8 -fold increase in bioavailability ${ }^{44}$. These findings display the efficacy of phospholipid encapsulation over other delivery techniques.

Liposomes can be effective for ALA because similarly to CUR; it has a rapid metabolism and a large degradation rate in first pass through the liver. BEN, though already a lipid soluble derivative of thiamine, may benefit from liposomal encapsulation based on the aforementioned mixed results with administration. To our knowledge no one has evaluated these three supplements in combination via oral liposomal encapsulated administration.

\section{Statement of the Problem}

Diabetes is a disease that can lead to the onset of multiple other comorbidities such as cardiovascular disease, dyslipidemia and polyneuropathies. Metabolic dysfunctions such as hyperglycemia, excess ROS generation, tissue inflammation, and dyslipidemia make treating and preventing diabetes a multifaceted problem that requires a multifaceted solution. Nutraceutical supplements; CUR, ALA, and BEN independently offer benefits via antioxidant and antiinflammatory actions. Additionally, these supplements can make favorable alterations to glucose and lipid metabolism. The combination of these supplements has yet to be studied in humans and may provide that multifaceted approach needed in preventing diabetes.

We will measure multiple functional outcomes from a 28-day supplementation. Glucose tolerance and insulin sensitivity will be measured via oral glucose tolerance tests and Matsuda 
index. During the last 7 days of supplementation, subjects will abstain from exercise and undergo a high fat overfeeding in order to temporarily induce insulin resistance. Changes in skeletal muscle and adipose tissue can have a large impact on insulin sensitivity and metabolic function ${ }^{72}$. It is also well established that visceral adiposity is highly associated with insulin resistance 73,74. Therefore, we will assess body mass and composition with dual x-ray absorptiometry and waist and hip girth measurements.

\section{Hypothesis}

We hypothesize that 28 days of dietary liposomal encapsulated CUR, ALA and BEN will result in increased circulating CUR and ALA and attenuate insulin resistance induced by high fat diet and exercise abstention in healthy, usually active college aged adults.

\section{Specific Aims}

1. To determine if liposome encapsulated supplements (L-ABC) can increase the bioavailability of curcumin and alpha lipoic acid over non-liposomal administration (ABC).

2. To determine if 28 days of dietary ( $\mathrm{L}-\mathrm{ABC}$ ) can attenuate insulin resistance induced by high fat overfeeding and exercise abstention compared to placebo (PL) and (ABC). 


\section{CHAPTER II}

\section{INTRODUCTION}

Diabetes is a disease plaguing over 422 million adults worldwide ${ }^{1}$. Type 2 diabetes (T2D) is characterized by insulin resistance and is often diagnosed with multiple comorbidities such as obesity, dyslipidemia, and cardiovascular disease ${ }^{2}$. Effective prevention and treatments include intensive dietary and physical activity changes ${ }^{1}$. Dietary and physical activity interventions, though initially effective, are not usually sustainable, in part due to noncompliance $^{3}$. Given the issue of non-compliance, alternative treatment and prevention methods need to be considered and scientifically evaluated. For example, dietary supplements are commonly used by many Americans as alternatives to exercise and dieting ${ }^{75}$, despite an appreciable imbalance between advertised and actual effects ${ }^{76}$.

Among the plethora of dietary supplements purported to have beneficial effects, several have fared well following scientific scrutiny. These include Alpha-lipoic acid (ALA), Benfotiamine (BEN), and Curcumin (CUR). All three of these individual supplements are reported to have anti-inflammatory and antioxidant properties ${ }^{6-9}$. Beyond anti-inflammatory and antioxidant properties, CUR and ALA have metabolic benefits such as decreasing fat synthesis and storage while increasing fat degradation, increasing metabolic rate, decreasing body weight, and improving insulin sensitivity ${ }^{6,10,51}$. ALA's antioxidant properties can also reduce oxidized forms of other antioxidants thereby replenishing the antioxidant molecule pool ${ }^{8}$. Thiamine, the active molecule of BEN, has been shown to improve glucose tolerance in individuals with hyperglycemia ${ }^{62}$ and favorably modify diabetic polyneuropathies ${ }^{65}$. 
A common limitation of CUR, ALA and thiamine supplementation is poor bioavailability after oral consumption ${ }^{67,77,78}$. However, it is possible to improve the bioavailability of CUR when administered via liposomes or micelles ${ }^{44}$, and thiamine when administered as BEN ${ }^{61}$.

Although evidence exists as to the beneficial effects of CUR, ALA, and BEN administered individually, little attention has been given the potential increased benefit of administering these supplements in combination. Accordingly, we hypothesized that 28 days of dietary liposomal encapsulated (L) CUR, ALA and BEN (ABC) would result in increased circulating CUR and ALA (compared with placebo and un-encapsulated ABC), and attenuate insulin resistance induced by a combination of exercise abstention and high fat diet in usually healthy, active college aged adults.

\section{METHODS}

\section{Subjects}

Inclusion criteria consisted of an age range between 18 and 30 years, body mass index less than $30 \mathrm{~kg} / \mathrm{m}^{2}$, weight stable for the previous 6-12 months and regular exercise at least 2-3 times per week. Exclusion criteria included current use of dietary supplements, current or previous tobacco use within two years, current use of metabolic or cardiovascular medications, pregnant or breast-feeding, and fasting glucose concentration above $100 \mathrm{mg} / \mathrm{dl}$. All procedures took place in the Human Performance Clinical Research Laboratory at Colorado State University. All subjects provided informed consent and the protocol was approved by the Institutional Review Board at Colorado State University, Fort Collins, CO. 


\section{Subject Screening}

The first visit to the laboratory comprised screening and baseline measurements. These consisted of body composition measurements using Dual Energy X-ray absorptiometry (DEXA; Hologic, DiscoveryW, QDR Series, Bedford, MA, USA), 3-day food recalls.

\section{Experimental Design}

A double-blind, placebo-controlled, repeated measures parallel design was used for this study. A timeline schematic of the study design is depicted in Figure 1. Subjects made six visits to the laboratory. The first visit comprised screening with anthropometric assessments, activity and dietary questionnaires. Visit two involved an assessment of resting metabolic rate (RMR). During visit three, an oral glucose tolerance test (OGTT) was administered (base). Following visit three, each subject was randomly assigned to one of three groups: Placebo (PL), nonliposomal ALA, BEN, and CUR (ABC), and liposomal ALA, BEN, and CUR (L-ABC). The sex distribution between each group was matched. Visit four entailed a meeting with a registered dietitian to instruct participants on their dietary intervention and took place between days 14-21 of supplementation. Visit five took place on day 22 of supplementation; subjects arrived at the laboratory for body composition assessments, blood pressure measurements, and a second OGTT (PreHFO). Immediately following this OGTT, participants began a seven day sedentary high fat overfeeding intervention (HFO) at the campus dining hall facilities (Housing and Dining Services, Colorado State University, Fort Collins, CO). Twenty-nine days after beginning supplementation, subjects underwent a final OGTT, body composition assessment and blood pressure measurements (PostHFO). 


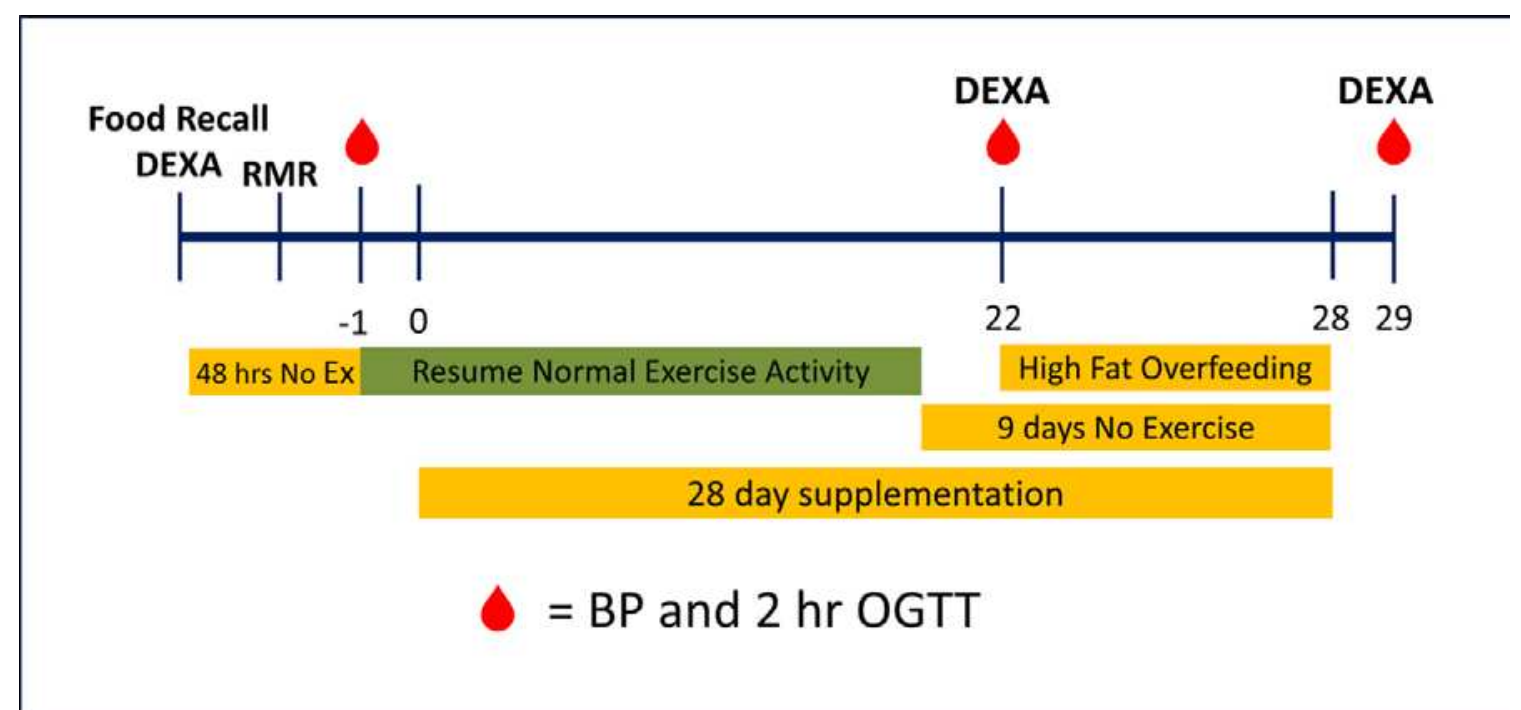

Figure 1 Schematic outline of the study design. Subjects completed a screening visit that included anthropometric measurements, and dietary recalls. Subjects then underwent a measurement of resting metabolic rate (RMR) and $2 \mathrm{hr}$ oral glucose tolerance test (OGTT) prior to supplementation denoted as day 0 . Subjects maintained normal activity levels after the first OGTT to day 20. Subjects began 9 days of exercise abstention two days prior to the OGTT on day 22 (PreHFO) and continued the abstention until day 29 (PostHFO), following the last day of high fat overfeeding

\section{Supplement}

The supplements and placebo were provided by Empirical Labs (Fort Collins, CO, USA). Both $\mathrm{ABC}$ and $\mathrm{L}-\mathrm{ABC}$ groups consumed 2.0g CUR, 0.5g ALA and 0.5g of BEN each day for 28 days. The supplement was self-administered twice daily, once in the morning and once in the evening, in $1.0 \mathrm{~g}$ Cur, $0.25 \mathrm{~g}$ ALA, and $0.25 \mathrm{~g}$ BEN doses. All supplements were provided in liquid form. Subjects were instructed to mix the supplement with a tolerable amount of orange juice (Kroger Brand serving size 8 oz, 100kcal, 24g CHO 20g from sugar, 0g FAT, 1g PRO). This ranged from $4 \mathrm{oz}$ to $10 \mathrm{oz}$ during supplementation, though for all of the OGTT visits subjects were instructed to consume exactly $8 \mathrm{oz}$ of orange juice in the morning. 


\section{Resting metabolic rate}

Resting metabolic rate (RMR) was measured using a ventilated hood and indirect calorimetry system comprising either a gas analyzer (Perkin Elmer MGA 1100, MA Tech Services, INC. St. Loius, MO) and ultrasonic flow sensor, (nnd Medizintechnik AG Zurich, Switzerland) (Nighthawk Design, Boulder, CO) or a metabolic cart (one subject only)( Parvo TrueOne 2400 Metabolic Measurement System, Parvo Medics, Sandy, UT). For assessment of RMR, subjects arrived at the laboratory in the morning after fasting for 12 hours and avoiding vigorous exercise for 24 hours. Blood pressure was measured every 15 minutes during the RMR using a physiological monitor (IntelliVue MP5, Philips Medical Systems, Andover, MA), U.S.).

\section{Body Composition and Blood Pressure}

Subjects arrived at the laboratory in the morning, avoiding vigorous exercise 48 hours prior to testing. Subjects also completed a 12 hour fast with the exception of taking a single dose of supplement with exactly $8 \mathrm{oz}$ of orange juice $30-45$ minutes prior to arrival to the laboratory. Upon arrival, subjects immediately underwent anthropometric measures for hip and waist circumference, and weight followed by a DEXA scan. After body composition, subjects were escorted to a clinical space for blood pressure measurements and OGTT. Blood pressures were measured after 5 minutes resting in a supine position with a physiological monitor. Blood pressure measurements were taken until two repeated measures were within $5 \mathrm{mmHg}$ of each other, i.e. (122/80 $\mathrm{mmHg}$ and 124/78 $\mathrm{mmHg}$ would be acceptable values); mean systolic and diastolic values were used for data analysis. 


\section{Oral Glucose Tolerance Test}

Following blood pressure measurements an intravenous catheter was placed in the antecubital space of the subject's arm. The first blood draw was timed so that the baseline blood draw was taken 60 minutes $( \pm 5 \mathrm{~min})$ following the consumption of the supplement with $8 \mathrm{oz}$ of orange juice. For consistency, prior to the Base OGTT subjects consumed $8 \mathrm{oz}$ of orange juice with no supplement. Subjects then consumed $75 \mathrm{~g}$ of dextrose dissolved in $300 \mathrm{~mL}$ of water within 5 minutes. Blood was sampled and circulating glucose values determined immediately prior to glucose consumption (Pre) and at $0,5,10,15,30,45,60,75,90,105$, and 120 minutes following glucose consumption. Circulating glucose was analyzed using an automated device (2300 STAT Plus Glucose Lactate Analyzer, YSI Inc., Yellow Springs, OH, USA).

Approximately $10 \mathrm{~mL}$ of venous blood was preserved with $\mathrm{K} 3$ ethylenediaminetetraacetic acid (Vacuette EDTA tubes, Grenier Bio-One North America, Inc., Monroe, NC, USA) and another $10 \mathrm{~mL}$ transferred into a serum separator tube (Vacutainer SST Tube with Silica Clot Activator, Polymer Gel, Silicone-Coated Interior, BD, Franklin Lakes, NJ, USA) at Pre, 15, 45, 60, 90, and 120 minutes after dextrose consumption. An additional $10 \mathrm{ml}$ of blood was collected prior to dextrose consumption at all three OGTTs and preserved with EDTA vacutainers for subsequent analysis with liquid chromatography for circulating ALA and CUR concentrations. Blood samples collected in chilled EDTA tubes were immediately placed on ice before being transferred to a chilled $\left(4^{\circ} \mathrm{C}\right)$ centrifuge. Samples were spun $(3600 \mathrm{rpm})$ within 60 minutes of collection to isolate plasma. Samples collected in SST tubes were kept at room temperature for approximately 15 minutes before being centrifuged to isolate serum. All plasma and serum samples were stored at $-80^{\circ} \mathrm{C}$ until analysis. Plasma insulin concentrations were measured in duplicate using an Human Insulin Enzyme-linked immunosorbent assay (ELISA) kit 
(Crystal Chem, Downers Grove, IL). Insulin sensitivity was estimated using the Matsuda Index 79 .

$U P L C-M S / M S$

To assess circulating ALA and CUR in the subjects, $\sim 1 \mathrm{~mL}$ of EDTA preserved plasma was thawed. Four-hundred $\mu \mathrm{L}$ of plasma was diluted with $400 \mu \mathrm{L}$ of acetonitrile containing 600 ng/mL Naproxen and $400 \mathrm{ng} / \mathrm{mL}$ D6-curcumin as internal standards. Samples were then vortexed for 30 seconds and centrifuged at 14,000 rpm. Liquid supernatant was placed in glass LC vial for LC-MS/MS analysis.

The instrument used in the analysis was an Agilent 1290 UPLC coupled to an Agilent 6460 triple quadruple mass spectrometer, which was equipped with an ESI source using Agilent Jet Stream Technology (Agilent, Santa Clara, CA). CUR and ALA were separated on an Agilent Poroshell 120 Phenyl Hexyl column $(2.1$ x $100 \mathrm{~mm}, 2.7 \mu \mathrm{m})$. A sample volume of $6 \mu \mathrm{L}$ was injected and a mixture of water with $0.1 \%$ Formic acid (A) and acetonitrile with $0.1 \%$ formic acid (B) at a flow rate of $0.4 \mathrm{~mL} / \mathrm{min}$. The gradient used was $40 \% \mathrm{~B}$ increasing to $70 \% \mathrm{~B}$ at 2.7 min, followed by and increase to $100 \%$ B by $3.0 \mathrm{~min}$. The ionization source conditions used were as follows: nebulizer $45 \mathrm{psi}$; gas flow of $10 \mathrm{~L} / \mathrm{min}$ at $325^{\circ} \mathrm{C}$; sheath gas flow of $12 \mathrm{~L} / \mathrm{min}$ at $400^{\circ} \mathrm{C}$; and the capillary voltage (-)3500 $\mathrm{V}$ and switched to $(+) 3500 \mathrm{~V}$ at $2 \mathrm{~min}$. Ionization polarity was switched from negative (ALA and Naproxen) to positive (CUR and D6-CUR) at 2 mins. The ion transitions monitored were $205.1 \rightarrow 171.1 / 127 \mathrm{~m} / \mathrm{z}$ for ALA, $229.1 \rightarrow$ 169.1/185 for Naproxen, 369.1 $\rightarrow$ 89.1/145.1 for CUR, and 375.1 $\rightarrow$ 89.1/145.1 for D6-CUR. ALA and CUR identifications were confirmed by retention time and the product ion ratio correlation between the sample peaks and corresponding standards $( \pm 20 \%)$. The data collection and processing were performed by using Agilent MassHunter Quantitative software (v.B.06.01). 


\section{Seven day High Fat Overfeeding}

A registered dietitian analyzed the 3 day food recall for macronutrient content using the Nutritionist Pro Diet Analysis Soft-ware (Axxya Systems, Stafford, TX). These data were then used to prescribe calorie intake during the overfeeding. Over a seven day period participants were prescribed to eat $150 \%$ of their normal caloric intake per day. Participants were to consume $50 \%$ of the newly prescribed total calorie intake from fat. Participants consumed the prescribed intake in three meals a day for seven days. To check dietary intake, food images from the third and seventh day of overfeeding were analyzed for total daily kcals, and fat content.

Estimated normal daily calorie intake was calculated using baseline RMR and multiplying by a sedentary physical activity factor of 1.55 . This activity factor was chosen because the healthy and normally active subjects abstained from exercise during the seven day overfeeding. To assess dietary intake, the estimated normal daily calorie intake was compared to total calorie consumption on the third an seventh days of overfeeding.

\section{Statistics}

Two-way analyses of variance (ANOVA; supplement $\mathrm{x}$ time) with repeated measures on one factor (time) were used to examine differences in the primary outcomes: body mass and composition, dietary compliance, insulin sensitivity, blood pressure, and circulating ALA. Multiple comparisons of factor means were performed using the Tukey post -hoc test. The level of statistical significance was set at $\mathrm{P}<0.05$. Data are expressed as mean \pm standard error (SE). 


\section{RESULTS}

\section{Subject Characteristics and Body Composition}

A total of 29 healthy, habitually physically active individuals between the ages of 18 and 30 were randomly assigned to PL $(n=9), \operatorname{ABC}(n=10)$ and L-ABC $(n=10)$. No Differences in anthropometrics existed between groups at baseline Table 1. Following sedentary HFO, body mass, body mass index, fat mass, lean mass, fat free mass, hip girth, and waist girth increased compared to Base and PreHFO. The increases in percent fat did not reach statistical significance. There was a group $\mathrm{x}$ time interaction in waist girth $(\mathrm{p}=0.045)$. Post-hoc analysis revealed that sedentary HFO increased waist circumference in PL and ABC groups but not in L$\mathrm{ABC}$. 
Table 1 Subject Characteristics and Body Composition

\begin{tabular}{|c|c|c|c|c|c|c|c|c|c|c|c|c|}
\hline & \multicolumn{3}{|c|}{ Placebo } & \multicolumn{3}{|c|}{$\mathbf{A B C}$} & \multicolumn{3}{|c|}{ L-ABC } & \multicolumn{3}{|c|}{ Main Effects } \\
\hline & \multicolumn{3}{|c|}{$\mathrm{n}=9$ (4 Female) } & \multicolumn{3}{|c|}{$\mathrm{n}=10(5$ Female $)$} & \multicolumn{3}{|c|}{$\mathrm{n}=10(5$ Female $)$} & \multirow{2}{*}{$\begin{array}{c}\text { Time } \\
\text { p-values }\end{array}$} & \multirow{2}{*}{$\begin{array}{c}\text { Group } \\
\text { p-values }\end{array}$} & \multirow{2}{*}{$\begin{array}{c}\text { Interactior } \\
\text { p-values }\end{array}$} \\
\hline & Base & PreHFO & PostHFO & Base & PreHFO & PostHFO & Base & PreHFO & PostHFO & & & \\
\hline Age (yrs) & $22(1)$ & - & - & $23(1)$ & - & - & $22(1)$ & - & - & - & $\mathrm{p}=0.701$ & - \\
\hline Height (m) & $1.72(0.03)$ & - & - & $1.74(0.03)$ & - & - & $1.74(0.03)$ & - & - & - & $\mathrm{p}=0.919$ & - \\
\hline Body Mass (kg) & $68.1(4.3)$ & $68.2(4.3)$ & $69.8(4.4)$ & $66.1(2.9)$ & $66.7(3.0)$ & $68.1(4.4)$ & $67.1(4.9)$ & $67.2(4.8)$ & $68.4(4.9)$ & $p<0.001$ & $\mathrm{p}=0.957$ & $\mathrm{p}=0.741$ \\
\hline Body Mass Index $\left(\mathrm{kg} / \mathrm{m}^{2}\right)$ & $22.8(0.9)$ & $22.9(0.9)$ & $23.4(0.9)$ & $21.9(0.9)$ & $22.9(0.9)$ & $23.4(0.9)$ & $22.0(0.9)$ & $22.1(0.9)$ & $22.5(1.0)$ & $\mathrm{p}<0.001$ & $\mathrm{p}=0.752$ & $\mathrm{p}=0.852$ \\
\hline Fat Mass (kg) & $14.62(1.11)$ & $14.83(1.08)$ & $16.61(1.13)$ & $15.60(1.94)$ & $16.09(2.03)$ & $16.61(2.10)$ & $14.58(1.49)$ & $14.61(1.47)$ & $14.97(1.59)$ & $\mathrm{p}<0.001$ & $\mathrm{p}=0.805$ & $\mathrm{p}=0.575$ \\
\hline Body Fat $\%$ & $22.1(1.6)$ & $22.5(1.8)$ & $22.6(1.8)$ & $24.3(3.1)$ & $24.6(3.1)$ & $25.1(3.2)$ & $22.4(2.3)$ & $22.4(2.3)$ & $22.7(2.4)$ & $\mathrm{p}=0.071$ & $\mathrm{p}=0.770$ & $\mathrm{p}=0.797$ \\
\hline Lean Mass (kg) & $50.11(3.75)$ & $50.24(3.95)$ & $51.41(4.02)$ & $47.36(3.35)$ & $47.64(3.47)$ & $48.17(3.57)$ & $49.43(4.15)$ & $49.53(4.21)$ & $50.04(4.35)$ & $\mathrm{p}<0.001$ & $\mathrm{p}=0.869$ & $\mathrm{p}=0.691$ \\
\hline Fat Free Mass (kg) & $52.65(3.92)$ & $52.77(4.12)$ & $52.58(4.52)$ & $49.85(3.49)$ & $50.14(3.60)$ & $50.64(3.73)$ & $51.97(4.31)$ & $52.05(4.37)$ & $52.58(4.52)$ & $p<0.001$ & $\mathrm{p}=0.874$ & $\mathrm{p}=0.663$ \\
\hline Hip Girth (cm) & $95.3(1.7)$ & $95.7(1.7)$ & $97.2(2.1)$ & $96.0(2.4)$ & $96.5(2.3)$ & $97.2(2.4)$ & $94.8(2.7)$ & $94.6(2.1)$ & $96.1(2.4)$ & $p<0.001$ & $\mathrm{p}=0.897$ & $\mathrm{p}=0.919$ \\
\hline Waist Girth $(\mathrm{cm})$ & $76.2(2.7)$ & $77.1(2.5)$ & $78.9(2.8)^{\mathbf{a}, \mathbf{b}}$ & $77.7(2.0)$ & $78.9(1.9)$ & $81.0(2.1)^{\mathbf{a}, \mathbf{b}}$ & $77.3(2.7)$ & $76.8(2.5)$ & $77.9(2.6)$ & $\mathrm{p}<0.001$ & $\mathrm{p}=0.827$ & $\mathrm{p}=0.045$ \\
\hline
\end{tabular}

Data represented as mean (SE)

Main effect of time was the same for all variables. Base and PreHFO were lower than PostHFO.

Superscript a signifies a difference within group between Base and PostHFO.

Superscript b signifies a difference within group between PreHFO and PostHFO.

Body Mass $(\mathrm{kg})$, body mass index $\left(\mathrm{kg} / \mathrm{m}^{2}\right)$, fat mass $(\mathrm{kg})$, body fat percent, lean mass $(\mathrm{kg})$, fat free mass $(\mathrm{kg})$, hip girth (cm), and waist girth $(\mathrm{cm})$ at baseline, pre and post high fat overfeeding $(\mathrm{HFO})$ within each supplement group. $(\mathrm{ABC}=$ non-liposomal supplement; L-ABC= Liposomal supplement) 


\section{Bioavailability}

Circulating CUR was undetectable in all groups on all test days. Circulating ALA was undetectable in all groups at baseline. Circulating ALA was detected in both ABC and L-ABC groups on both PreHFO and PostHFO test days. L-ABC had higher circulating ALA compared to $\mathrm{ABC}$ independent of time $(\mathrm{P}=0.002)$. Post-hoc analysis revealed that sedentary HFO resulted in lower ALA concentrations in the L-ABC (PreHFO vs. PostHFO $\mathrm{p}=0.019$ ) (Figure 2).

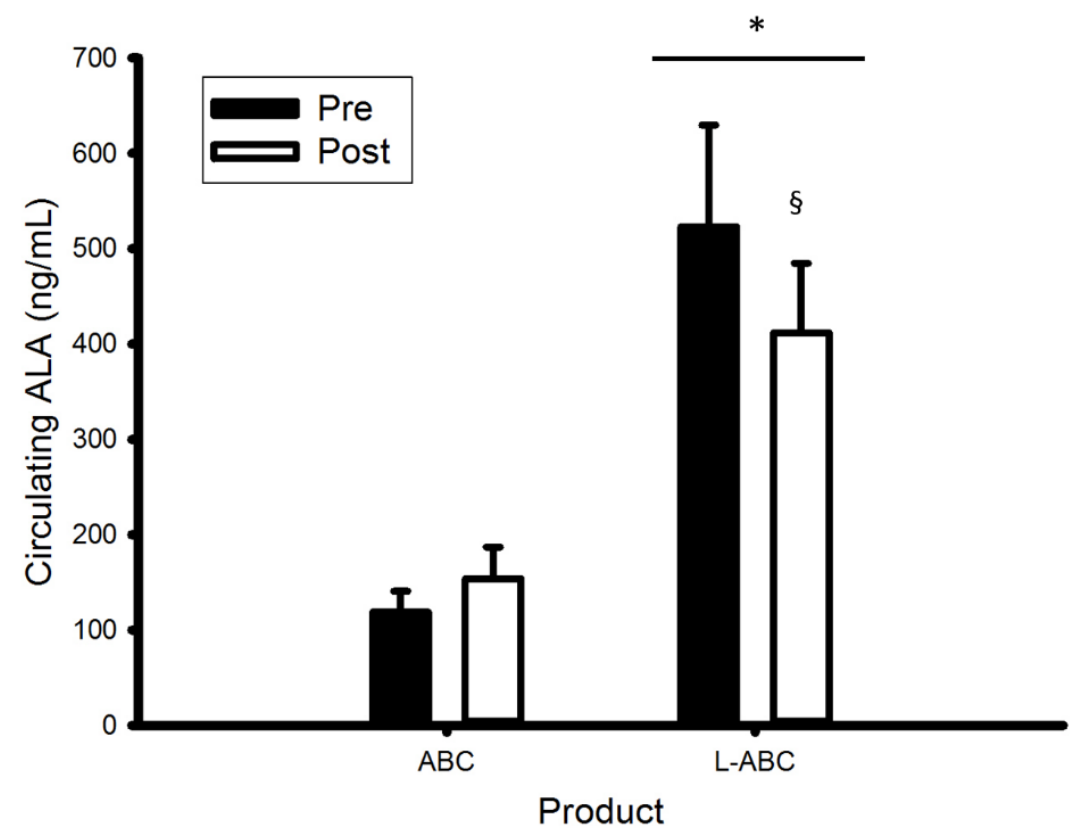

Figure 2 Circulating Alpha-Lipoic Acid (ALA) (ng/mL) mean and SE after a 12 hour fast and 60 minutes post-supplement consumption in both supplement groups, pre (black) and post (white) high fat overfeeding. ALA concentrations were undetectable in the placebo group. *Main effect of group ( $\mathrm{p}=0.002)$ for liposomal supplement consumption (L-ABC) vs. non-liposomal consumption $(\mathrm{ABC})$. $\S$ Significant difference compared to Pre within group. 


\section{Dietary Intake}

Data from 23 subjects are shown for days three and seven due to missing food images. There was no difference in dietary intake between groups $(\mathrm{p}=0.618)$ for estimated normal and day three or seven of HFO intake. Total calorie intake on days three and seven were higher than estimated normal calorie intake $(\mathrm{p}<0.05)$. There was no difference between groups $(\mathrm{p}=0.562)$ or days of HFO $(\mathrm{p}=0.824)$ for percentage of calories consumed as fat (Table 2).

Table 2 Dietary intake

\begin{tabular}{|c|c|c|c|c|c|c|c|c|c|}
\hline & \multicolumn{3}{|c|}{$\begin{array}{c}\text { Placebo } \\
n=8(3 \text { Female })\end{array}$} & \multicolumn{3}{|c|}{$\begin{array}{c}\mathbf{A B C} \\
n=6(3 \text { Female })\end{array}$} & \multicolumn{3}{|c|}{$\begin{array}{c}\text { L-ABC } \\
n=9(4 \text { Female })\end{array}$} \\
\hline & Est. Norm & Day 3 & Day7 & Est. Norm & Day 3 & Day7 & Est. Norm & Day 3 & Day7 \\
\hline Kcal/day & 2494 (159) & $3492(252)^{*}$ & $3644(384)^{*}$ & $2280(142)$ & $3041(319)^{*}$ & $3270(447)^{*}$ & $2491(175)$ & $3422(434)^{*}$ & $3299(405)^{*}$ \\
\hline$\%$ Fat & - & $53(1)$ & $51(1)$ & - & $50(2)$ & $51(1)$ & - & $51(2)$ & $53(2)$ \\
\hline
\end{tabular}

Data represented as mean (SE)

Est. Norm $=$ resting metabolic rate $\mathrm{x} 1.55$ activity factor for sedentary individuals

* signifies a siginificant difference from estimated normal intake.

Total caloric intake and percent fat consumed for each supplement group on days three and seven of sedentary high fat overfeeding. Estimated normal calorie intake is displayed for reference. $(\mathrm{ABC}=$ non-liposomal supplement; $\mathrm{L}-\mathrm{ABC}=$ Liposomal supplement $)$.

\section{Blood Pressure}

Blood pressures were measured in 20 subjects (Table3). There was a main effect of time for systolic, diastolic and mean arterial (MAP) blood pressures. Post-hoc analysis revealed that sedentary HFO resulted in increased blood pressure compared to PreHFO (Sys p=0.027, Dia $\mathrm{p}=0.019$, MAP $\mathrm{p}=0.009)$, but not Base $($ Sys $\mathrm{p}=0.185$, Dia $\mathrm{p}=0.15$, MAP $\mathrm{p}=0.102)$ (Table 3$)$. 
Table 3 Blood Pressure

\begin{tabular}{|c|c|c|c|c|c|c|c|c|c|c|c|c|}
\hline \multirow{3}{*}{ Table 3 Blood } & \multirow{2}{*}{\multicolumn{3}{|c|}{$\begin{array}{c}\text { Placebo } \\
\mathrm{n}=6(3 \text { Female })\end{array}$}} & \multirow{2}{*}{\multicolumn{3}{|c|}{$\begin{array}{c}\mathbf{A B C} \\
\mathrm{n}=6 \text { (3 Female) }\end{array}$}} & \multirow{2}{*}{\multicolumn{3}{|c|}{$\begin{array}{c}\text { L-ABC } \\
\mathrm{n}=7 \text { (4 Female) }\end{array}$}} & \multicolumn{3}{|c|}{ Main Effects } \\
\hline & & & & & & & & & & Time & Group & Interaction \\
\hline & Base & PreHFO & PostHFO & Base & PreHFO & PostHFO & Base & PreHFO & PostHFO & p-values & p-values & p-values \\
\hline Systolic (mmHg) & $105(4)$ & $106(4)$ & $111(4)$ & $110(3)$ & $108(4)$ & $112(4)$ & $113(3)$ & $110(2)$ & $114(3)$ & $\mathrm{p}=0.032$ & $\mathrm{p}=0.461$ & $\mathrm{p}=0.689$ \\
\hline Diastolic (mmHg) & $64(3)$ & $62(3)$ & $65(3)$ & $63(2)$ & $61(2)$ & $67(3)$ & $67(2)$ & $65(30$ & $68(1)$ & $\mathrm{p}=0.023$ & $\mathrm{p}=0.366$ & $\mathrm{p}=0.643$ \\
\hline MAP (mmHg) & $78(3)$ & $77(3)$ & $82(2)$ & $78(1)$ & $77(2)$ & $82(2)$ & $82(2)$ & $80(2)$ & $83(1)$ & $\mathrm{p}=0.011$ & $\mathrm{p}=0.264$ & $\mathrm{p}=0.706$ \\
\hline
\end{tabular}

Data represented as mean (SE)

p-values describe a main effect of time, where PreHFO was less than PostHFO, independent of supplement group.

Systolic, diastolic and mean arterial (MAP) blood pressures represented as mean (SE) at baseline, pre and post high fat overfeeding (HFO) within each supplement group. $(\mathrm{ABC}=$ non-liposomal supplement; $\mathrm{L}-\mathrm{ABC}=\mathrm{Liposomal}$ supplement $)$. 


\section{Oral Glucose Tolerance Test and Insulin Sensitivity}

Figure 3 displays glucose over time during the OGTT. There were no differences between group or time for glucose area under the curve (AUC) $(\mathrm{p}=0.372)$ (Figure 3D). Fasting, peak, and 120 min glucose values did not differ between supplement groups or test days $(\mathrm{p}=0.193$ or $0.093, \mathrm{p}=0.404$ or 0.714 , and $\mathrm{p}=0.273$ or 0.092 , for each measure respectively) (Figure 3).

Insulin AUC was higher PostHFO compared to Base $(\mathrm{p}=0.003)$; the magnitude of increase compared to PreHFO was not statistically significant $(\mathrm{p}=0.055)$ (Figure 5D). There was a main effect of time for fasting insulin $(\mathrm{p}=0.037)$, peak insulin $(\mathrm{p}=0.013)$, and Matsuda index $(\mathrm{p}=0.017)$. For fasting $(\mathrm{p}=0.034)$ and peak insulin $(\mathrm{p}=0.010)$, post-hoc analysis revealed that PostHFO values were increased compared to Base (Figure 5). Post-hoc analysis for Matsuda index revealed that sedentary HFO decreased insulin sensitivity compared to Base values $(\mathrm{p}=0.014)$ (Figure 5). Quantitative insulin sensitivity check index (QUICKI) was lower following HFO $(0.35 \pm 0.01)$ compared to Base $(0.37 \pm 0.01)(\mathrm{p}=0.018)$. 

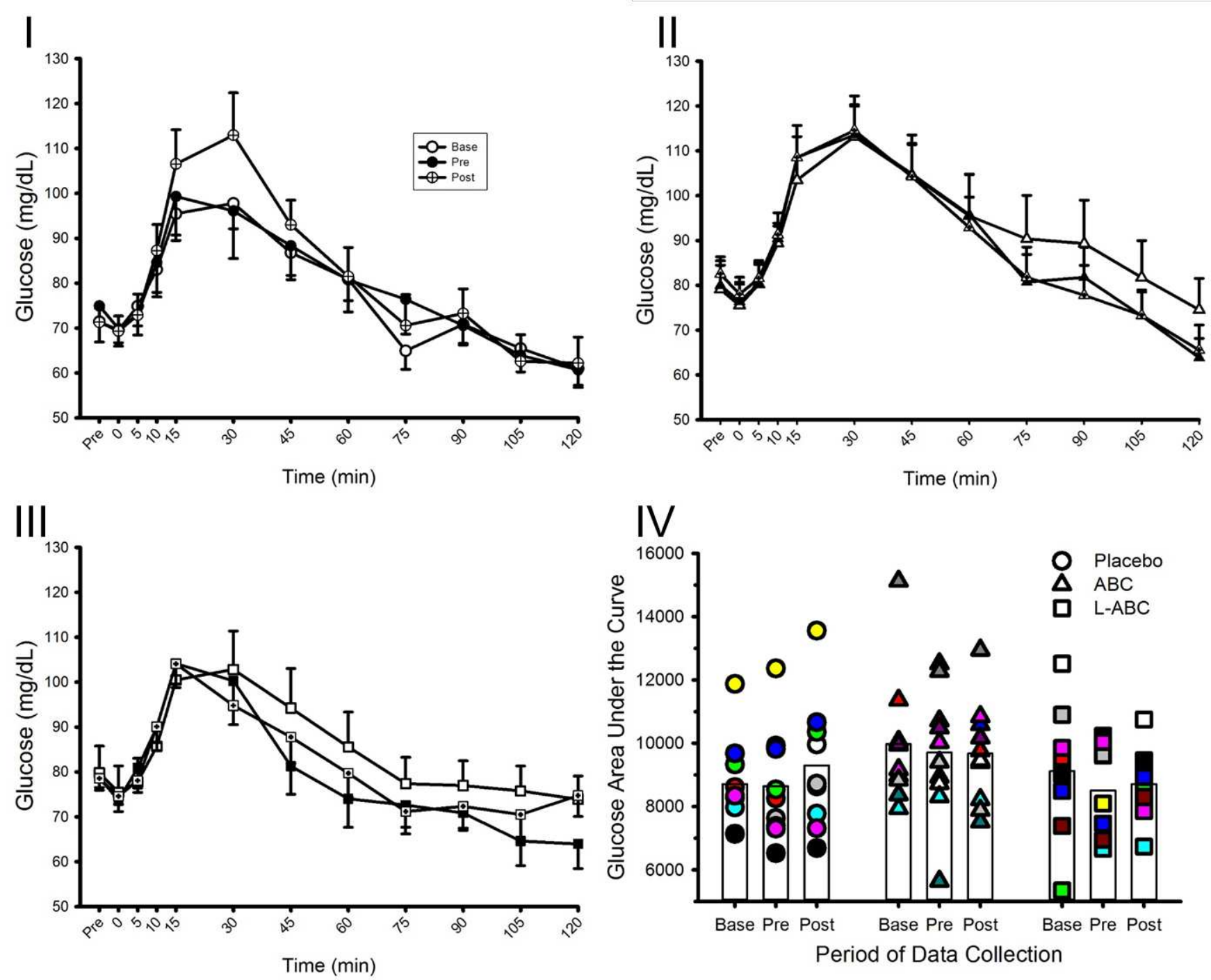

Figure 3 Circulating glucose $(\mathrm{mg} / \mathrm{dL})$ during two hour oral glucose tolerance tests for placebo, $\mathrm{ABC}$, and L-ABC in panels (I), (II) and (III) where open, filled and cross-haired points represent baseline, pre-high fat overfeeding and post-high fat overfeeding, respectively. Glucose area under the curve represented as mean with individual data at each period of data collection in panel (IV). Circles, triangles and squares represent placebo, $\mathrm{ABC}$ and $\mathrm{L}-\mathrm{ABC}$, respectively. $(\mathrm{ABC}=$ non-liposomal supplement; $\mathrm{L}-\mathrm{ABC}=\mathrm{Liposomal}$ supplement; base $=$ baseline; $\mathrm{Pre}=$ pre high fat overfeeding; Post= post high fat overfeeding). 

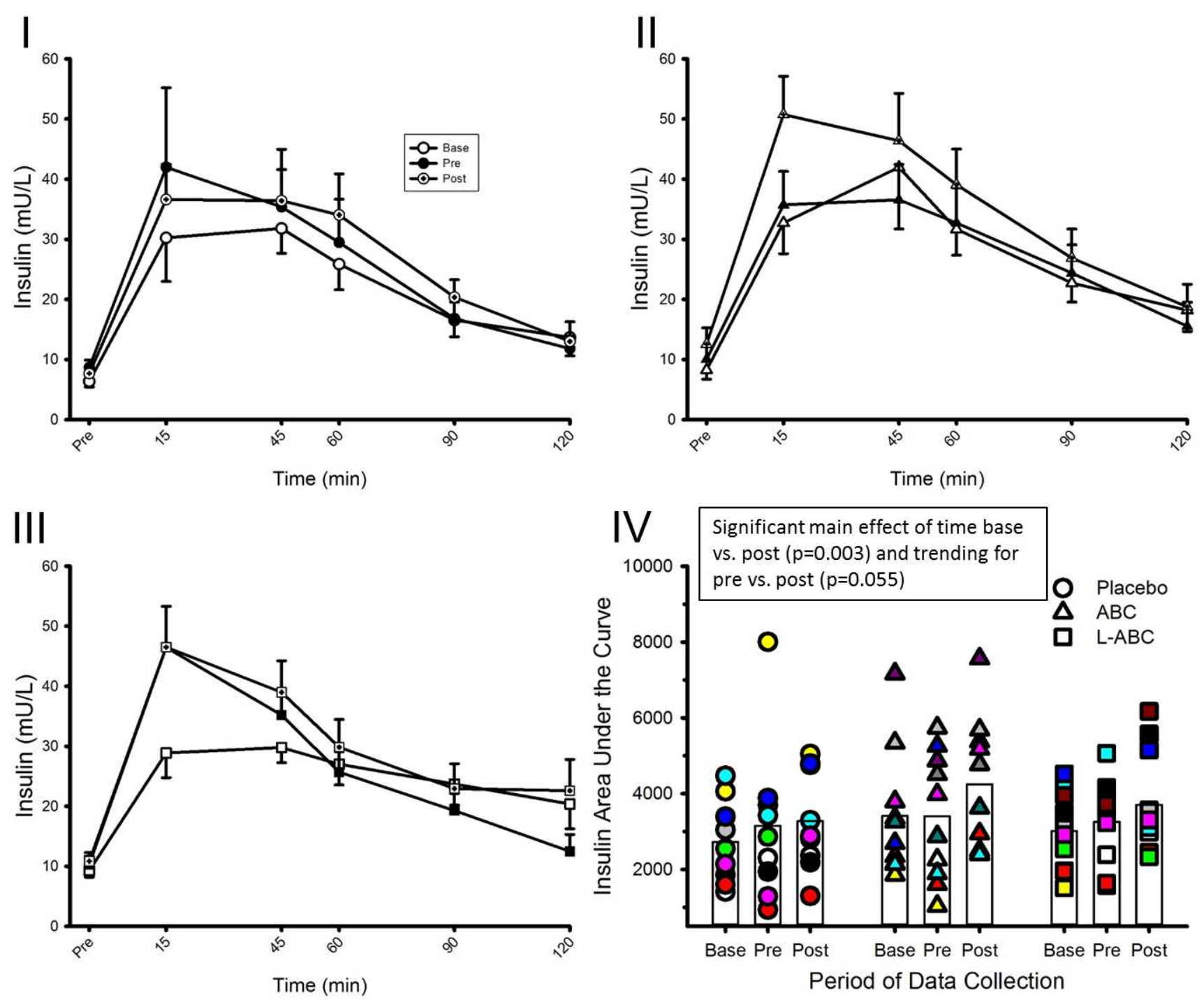

Figure 4 Circulating insulin (mU/L) during two hour oral glucose tolerance tests for placebo, $\mathrm{ABC}$, and L-ABC in panels (I), (II) and (III) where open, filled and cross-haired points represent baseline, pre-high fat overfeeding and post-high fat overfeeding, respectively. Insulin area under the curve represented as mean with individual data at each period of data collection in panel (IV). Circles, triangles and squares represent placebo, $\mathrm{ABC}$ and $\mathrm{L}-\mathrm{ABC}$, respectively. $(\mathrm{ABC}=$ non-liposomal supplement; $\mathrm{L}-\mathrm{ABC}=\mathrm{Liposomal}$ supplement; base= baseline; $\mathrm{Pre}=$ pre high fat overfeeding; Post= post high fat overfeeding). 


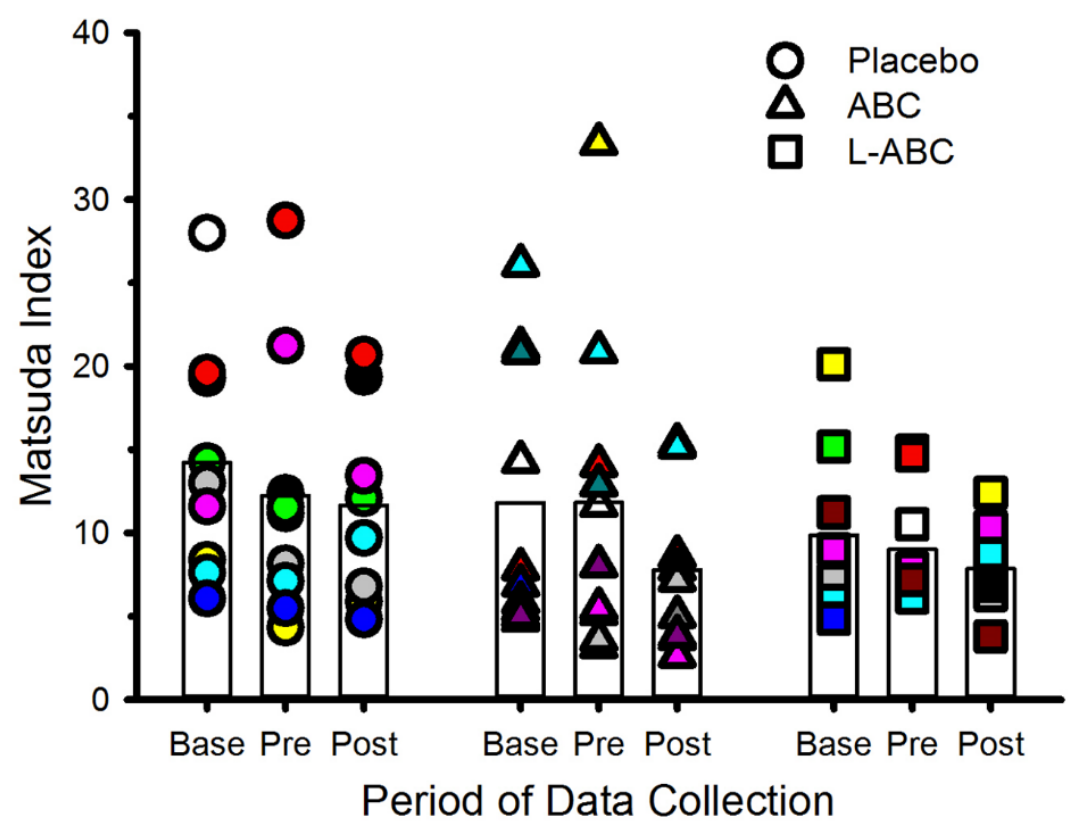

Figure 5 Matsuda Index represented as mean with individual data at each period of data collection. Circles, triangles and squares represent placebo, $\mathrm{ABC}$ and $\mathrm{L}-\mathrm{ABC}$, respectively. Main effect of time where Matsuda index decreased Post HFO compared to Base $(\mathrm{p}=0.014)$. $(\mathrm{ABC}=$ non-liposomal supplement; $\mathrm{L}-\mathrm{ABC}=\mathrm{Liposomal}$ supplement; base $=$ baseline; Pre $=$ pre high fat overfeeding; Post= post high fat overfeeding). 


\section{DISCUSSION}

The purpose of this study was to determine if liposomal encapsulated (L) ALA, BEN and CUR (ABC) would prevent the unfavorable metabolic consequences of sedentary high-fat overfeeding in healthy young adults. The major findings were L-ABC: 1) promoted alpha-lipoic acid bioavailability; and, 2) prevented sedentary high-fat overfeeding mediated increases in waist circumference in usually active healthy young adults. These data may have important public health implications for periods of inactivity coupled with overconsumption, such as during seasonal celebrations.

\section{Bioavailability}

Following oral ingestion, ALA undergoes rapid metabolism via first pass through the liver, and is subsequently degraded into over 10 different metabolites via $\beta$-oxidation of the carboxylic acid side chain ${ }^{58}$. This rapid degradation can impede the potential health benefits of ALA supplementation. Our current study provides evidence that supplementation with liposomal encapsulated ALA increases plasma concentrations of ALA (Figure 2), an observation that is consistent with previous animal studies ${ }^{80}$. In mice, increased circulating ALA has been purported to promote weight loss and increase metabolic rate via activation of uncoupling protein- ${ }^{50}$. In white subcutaneous adipocytes isolated from obese humans, ALA may also increase mitochondrial biogenesis and facilitate beiging ${ }^{81}$.

In contrast to ALA, we did not detect circulating CUR in plasma. Most orally consumed CUR is excreted in the feces, while the trace amounts present in circulation are rapidly metabolized to more water soluble metabolites, such as glucuronides and sulfates ${ }^{46,82}$. Therefore, our attempt to identify free CUR in the circulation could be construed as misguided, as 
measuring glucuronide and sulfate conjugates of CUR could have helped confirm/refute CUR absorption from the gut. This limitation is consistent with one previous study of CUR pharmacokinetics, where free CUR was detected in only one of 12 adults receiving oral CUR supplementation (10-12 g) ${ }^{46}$. Only CUR glucuronide and CUR sulfate conjugates were detected in the other adults. The activity of CUR sulfates and glucuronides has been scrutinized over the last decade. A phase II clinical trial in pancreatic cancer patients showed that despite an absence of free CUR, CUR glucuronides favorably influenced malignant cell growth ${ }^{45}$. More recently, CUR mono-and di-glucuronides have been shown to have no effect on the NF-kB pathway and human cell proliferation activity ${ }^{83}$ and CUR mono- and di-glucuronides had more than a 10-fold decrease in anti-oxidant capacity compared to CUR ${ }^{84}$. While these studies highlight the pleiotropic properties of CUR, they are limited to ex vivo analysis, and can only address the activity, or lack thereof, in the specific cell lines used. In regards to insulin action and glucose regulation, future research may benefit from CUR glucuronide experiments in tissues that play a large role in glucose metabolism i.e. (liver, skeletal muscle and fat).

\section{Body Composition}

The current study showed increased body and fat mass after seven days of sedentary overfeeding, an observation that is consistent with previous reports ${ }^{85-87}$ (Table 1). In the current study, L-ABC prevented sedentary HFO-induced increases in waist girth (Table 1). Preventing increases in waist circumference after a sedentary HFO suggests L-ABC supplementation may favorably affect regional fat deposition. It is well established that fat accumulation in the hip and thigh (gynoid) regions compared to trunk (android) deposition is associated with better metabolic and cardiovascular health ${ }^{73,88,89}$. This may imply efficacy for L-ABC in promoting healthier 
weight gain and potentially providing protection against future metabolic and cardiovascular disease.

\section{Blood Pressure}

The metabolic syndrome is in part characterized by insulin resistance and hypertension 52,90,91. Previous studies have found that supplementation with ALA prevented the rise of systolic pressures in mice with hyperglycemia induced hypertension ${ }^{52}$ while BEN prevented postprandial endothelial dysfunction in people with type 2 diabetes ${ }^{92}$. Although these supplements may have some benefits to cardiovascular health when administered alone, the influence of combined administration of $\mathrm{ABC}$ on blood pressure after $\mathrm{HFO}$ has not been reported. The rise in resting blood pressure after HFO was not influenced by ABC supplementation. Note the appreciable increase in caloric consumption was likely accompanied by increased sodium intake; the positive relationship between dietary sodium and blood pressure has been well established ${ }^{93}$ thus, the increased blood pressure we observed may, in part, be explained by increased sodium.

Although we observed a significant increase in blood pressure following HFO, the absolute values remained within the normal range established by the American Heart Association ${ }^{94}$. From a cohort of the Framingham Heart Study, normotensive participants still had a $17.6 \%$ risk of becoming hypertensive within the next four years ${ }^{95}$. The scope of the current study did not allow for the longitudinal assessment of preventing hypertension and, as depicted by the Framingham study, there may be long-term implications to blood pressure that need addressed.

\section{Glucose Regulation}


In the current study, glucose tolerance was unchanged following sedentary HFO (Figure 3); these data are contrary to our hypothesis. Further, the increases in circulating insulin reflected sedentary HFO induced impairments to insulin sensitivity as depicted by two calculated measures (Matsuda and QUICKI) (Figures 4 and 5). These findings are consistent with numerous other studies (rodent and human) that suggest nutritional excess, with or without exercise abstention, decreases insulin action ${ }^{11,12,85,96-98}$. The underlying mechanisms by which insulin action is negatively altered are still not well understood. Though a primary outcome of this study was to assess the influence of $\mathrm{ABC}$ on insulin resistance, potential mechanisms such as inflammation and oxidative stress were not measured. Inflammatory markers such as macrophage infiltration of adipocytes and circulating TNF $\alpha$ and IL-6 are consistently associated with obese individuals and decreases in insulin sensitivity ${ }^{13,23}$. Oxidative stress is concurrently present with inflammation and furthers pro-inflammatory action. Superoxides can activate the redox sensitive transcription factor, NF- $\mathrm{kB}$, which activates the transcription of many proinflammatory genes ${ }^{15}$. Future studies should measure the effects of $\mathrm{ABC}$ on these pathways to further describe potential mechanisms of action.

One possible reason for the lack of change in glucose tolerance may be due to studying a population that was active prior to participation. Participants in this study were lean and habitually active prior to the seven-day HFO and nine day exercise abstention. A recent study in mice showed that prior exercise training can attenuate sedentary high fat diet induced glucose intolerance compared to sedentary controls ${ }^{99}$.

Similar to the shortcomings of our blood pressure results, the HFO performed in this study may not have been long enough in duration to see changes in circulating glucose. In the development of T2D, insulin resistance could precede any measurable changes in circulating 
glucose. One study provided 12 healthy human subjects with an acute (5-day) high fat diet and observed decreased insulin sensitivity but no changes in fasting glucose post intervention ${ }^{100}$. The efficacy of $\mathrm{ABC}$ supplementation on glucose regulation may be better assessed in longitudinal studies with populations at higher risk of being diagnosed with diabetes. For example, one group supplemented CUR extract (1.5 g/day) in humans with prediabetes for nine months. Metabolic assessments related to glucose tolerance and insulin resistance differed from placebo group after three months of supplementation ${ }^{29}$. After 28 days of supplementation and one week of sedentary HFO the current study observed elevated circulating insulin but no changes in circulating glucose during an OGTT. The issue could be that the development of diabetes has a longer progression than the scope of the current experiment can make conclusions about. Future studies should either increase the duration of HFO intervention or as stated earlier, find populations with a higher risk of developing T2D.

\section{Public Health Implications}

Our findings have potential implications for global public health. Seasonal changes in weight gain are well documented, specifically with holiday celebrations ${ }^{101}$. One theory suggests after each holiday season the population does not get back to the original pre-celebration weight. The continuous change of these seasonal weight gains and losses may contribute to slow, long term weight gain termed as the small average daily imbalance between total energy intake and expenditure that can add to a larger gap over time ${ }^{102}$. The dietary intervention in the current study may be similar to times of seasonal celebrations and our findings may support L-ABC supplementation for preventing increases in waist circumference during these times. 


\section{Summary}

In conclusion, despite sedentary HFO induced weight gain and decreased insulin sensitivity, the current study found L-ABC supplementation: 1) increased bioavailability of ALA; and 2) prevented sedentary HFO mediated increases in waist circumference. These findings suggest that L-ABC may be helpful in promoting healthy fat deposition and subsequently protecting against metabolic and cardiovascular disease development. 


\section{REFERENCES}

1. World Health Organization. Global Report on Diabetes. 6 (2016).

2. Khaodhiar, L., McCowen, K. C. \& Blackburn, G. L. Obesity and its comorbid conditions. Clin. Cornerstone 2, 17-28 (1999).

3. Ochner, C. N., Tsai, A. G., Kushner, R. F. \& Wadden, T. A. Treating obesity seriously: When recommendations for lifestyle change confront biological adaptations. Lancet Diabetes Endocrinol. 3, 232-234 (2015).

4. Orozco, L. J. et al. Exercise or exercise and diet for preventing type 2 diabetes mellitus. Cochrane Database Syst. Rev. 2008 Issue 3. A, (2008).

5. Santini, A., Tenore, G. C. \& Novellino, E. Nutraceuticals : A paradigm of proactive medicine. Eruopean J. Pharmacuetical Sci. 96, 53-61 (2016).

6. Alappat, L. \& Awad, A. B. Curcumin and obesity: Evidence and mechanisms. Nutr. Rev. 68, 729-738 (2010).

7. El Midaoui, A. et al. Impact of $\alpha$-lipoic acid on liver peroxisome proliferator-activated receptor- $\alpha$, vascular remodeling, and oxidative stress in insulin-resistant rats. Can. J. Physiol. Pharmacol. 89, 743-751 (2011).

8. Golbidi, S., Badran, M. \& Laher, I. Diabetes and alpha lipoic acid. Front. Pharmacol. 2 NOV, 1-15 (2011).

9. Shay, K., Moreau, R. \& Smith, E. Alpha-lipoic acid as a dietary supplement: molecular mechanisms and therapeutic potential. Biochim. Biophys. ... 1790, 1149-1160 (2009).

10. Wang, S. et al. Novel insights of dietary polyphenols and obesity. J. Nutr. Biochem. 25, 118 (2014).

11. Barclay, J. L. et al. High-fat diet-induced hyperinsulinemia and tissue-specific insulin resistance in Cry-deficient mice. Am J Physiol Endocrinol Metab 304, E1053-63 (2013).

12. Boden, G. et al. Excessive caloric intake acutely causes oxidative stress, GLUT4 carbonylation, and insulin resistance in healthy men. Sci. Transl. Med. 7, 304re7-304re7 (2015).

13. Maury, E. \& Brichard, S. M. Adipokine dysregulation, adipose tissue inflammation and metabolic syndrome. Mol. Cell. Endocrinol. 314, 1-16 (2010).

14. Shoelson, S. E., Herrero, L. \& Naaz, A. Obesity, Inflammation, and Insulin Resistance. Gastroenterology 132, 2169-2180 (2007).

15. Dandona, P., Aljada, A. \& Bandyopadhyay, A. Inflammation: The link between insulin resistance, obesity and diabetes. Trends Immunol. 25, 4-7 (2004).

16. Boyer, F. et al. Oxidative stress and adipocyte biology: Focus on the role of AGEs. Oxid. Med. Cell. Longev. 2015, (2015). 
17. Esposito, K. et al. Inflammatory cytokine concentrations are acutely increased by hyperglycemia in humans: Role of oxidative stress. Circulation 106, 2067-2072 (2002).

18. Gaens, K. H., Stehouwer, C. D. \& Schalkwijk, C. G. Advanced glycation endproducts and its receptor for advanced glycation endproducts in obesity. Curr Opin Lipidol 24, 4-11 (2013).

19. Gerber, P. A. \& Rutter, G. A. The role of oxidative stress and hypoxia in pancreatic beta cell dysfunction in diabetes mellitus. J. Neurophysiol. 17-22 (2013). doi:10.4095/This

20. Frohnert, B. I., Long, E. K., Hahn, W. S. \& Bernlohr, D. A. Glutathionylated lipid aldehydes are products of adipocyte oxidative stress and activators of macrophage inflammation. Diabetes 63, 89-100 (2014).

21. Kislinger, T. et al. Nepsilon-(Carboxymethyl)Lysine Adducts of Proteins Are Ligands for Receptor for Advanced Glycation End Products That Activate Cell Signaling Pathways and Modulate Gene Expression. J. Biol. Chem. 274, 31740-31749 (1999).

22. Lee, Y. S. et al. Inflammation is necessary for long-term but not short-term high-fat dietinduced insulin resistance. Diabetes 60, 2474-2483 (2011).

23. de Luca, C. \& Olefsky, J. M. Inflammation and insulin resistance. FEBS Lett. 582, 97-105 (2008).

24. Möller, K. et al. Influence of weight reduction on blood levels of C-reactive protein, tumor necrosis factor- $\alpha$, interleukin-6, and oxylipins in obese subjects. Prostaglandins. Leukot. Essent. Fatty Acids 106, 39-49 (2015).

25. Lan, J. et al. Meta-analysis of the effect and safety of berberine in the treatment of type 2 diabetes mellitus, hyperlipemia and hypertension. J. Ethnopharmacol. 161, 69-81 (2015).

26. Kerimi, A. \& Williamson, G. At the interface of antioxidant signalling and cellular function: key polyphenol effects. Mol. Nutr. Food Res. 1-12 (2016). doi:10.1002/mnfr.201400013.This

27. Aggarwal, Bharat B. Harikumar, K. B. Potential Therapeutic Effects of Curcumin, the Anti-inflammatory Agent, Against Neurodegenerative, Cardiovascular, Pulmonary, Metabolic, Autoimmune and Neoplastic Diseases Bharat. International Journal of Biochemistry 41, (2010).

28. Hatcher, H., Planalp, R., Cho, J., Torti, F. M. \& Torti, S. V. Curcumin: From ancient medicine to current clinical trials. Cell. Mol. Life Sci. 65, 1631-1652 (2008).

29. Chuengsamarn, S., Rattanamongkolgul, S., Luechapudiporn, R., Phisalaphong, C. \& Jirawatnotai, S. Curcumin extract for prevention of type 2 diabetes. Diabetes Care 35, 2121-2127 (2012).

30. Shao, W. et al. Curcumin prevents high fat diet induced insulin resistance and obesity via attenuating lipogenesis in liver and inflammatory pathway in adipocytes. PLoS One 7, 113 (2012).

31. K. Ono, K. Hasegawa, H. N. and M. Y. Curcumin has potent anti-amyloidogenic effects 
for Alzheimer's beta-amyloid fibrils in vitro. J. Neurosci. Res., 75, 742-50 (2004).

32. Fleenor, B. S. et al. Curcumin Ameliorates Arterial Dysfunction and Oxidative Stress with Aging. NIH Public Access 48, 269-276 (2014).

33. Yang, X. et al. Curcumin inhibits platelet-derived growth factor-stimulated vascular smooth muscle cell function and injury-induced neointima formation. Arterioscler. Thromb. Vasc. Biol. 26, 85-90 (2006).

34. Jain, S. K., Rains, J. \& Jones, K. Effect of curcumin on protein glycosylation, lipid peroxidation, and oxygen radical generation in human red blood cells exposed to high glucose levels. Free Radic. Biol. Med. 41, 92-96 (2006).

35. Varatharajalu, R. et al. Protective Role of Dietary Curcumin in the Prevention of the Oxidative Stress Induced by Chronic Alcohol with respect to Hepatic Injury and Antiatherogenic Markers. Oxid. Med. Cell. Longev. 2016, 1-10 (2016).

36. Wang, Y. et al. Inhibition of JNK by novel curcumin analog C66 prevents diabetic cardiomyopathy with a preservation of cardiac metallothionein expression. Am. J. Physiol. Endocrinol. Metab. 306, E1239-47 (2014).

37. Yekollu, S. K., Thomas, R. \& O’Sullivan, B. Targeting curcusomes to inflammatory dendritic cells inhibits NF-??B and improves insulin resistance in obese mice. Diabetes 60, 2928-2938 (2011).

38. Kuo, J.-J., Chang, H.-H., Tsai, T.-H. \& Lee, T.-Y. Positive effect of curcumin on inflammation and mitochondrial dysfunction in obese mice with liver steatosis. Int. J. Mol. Med. 30, 673-679 (2012).

39. Jimenez-Flores, L. M., Lopez-Briones, S., Macias-Cervantes, M. H., Ramirez-Emiliano, J. \& Perez-Vazquez, V. A PPARgamma, NF-kappaB and AMPK-Dependent mechanism may be involved in the beneficial effects of curcumin in the diabetic $\mathrm{db} / \mathrm{db}$ mice liver. Molecules 19, 8289-8302 (2014).

40. Kim, T., Davis, J., Zhang, A. J., He, X. \& Mathews, S. T. Curcumin activates AMPK and suppresses gluconeogenic gene expression in hepatoma cells. Biochem. Biophys. Res. Commun. 388, 377-382 (2009).

41. Hardie, D. G. \& Carling, D. The AMP-activated protein kinase--fuel gauge of the mammalian cell? Eur.J Biochem. 246, 259-273 (1997).

42. Hayashi, T., Hirshman, M. F., Kurth, E. J., Winder, W. W. \& Goodyear, L. J. Evidence for 5' AMP-activated protein kinase mediation of the effect of muscle contraction on glucose transport. Diabetes 47, 1369-1373 (1998).

43. Ruderman, N. B., Saha, a K., Vavvas, D. \& Witters, L. a. Malonyl-CoA, fuel sensing, and insulin resistance. Am. J. Physiol. 276, E1-E18 (1999).

44. Kocher, A., Schiborr, C., Behnam, D. \& Frank, J. The oral bioavailability of curcuminoids in healthy humans is markedly enhanced by micellar solubilisation but not further improved by simultaneous ingestion of sesamin, ferulic acid, naringenin and xanthohumol. J. Funct. Foods 14, 183-191 (2015). 
45. Dhillon, N. et al. Phase II trial of curcumin in patients with advanced pancreatic cancer. Clin. Cancer Res. 14, 4491-4499 (2008).

46. Vareed, S. K. et al. Pharmacokinetics of curcumin conjugate metabolites in healthy human subjects. Cancer Epidemiol. Biomarkers Prev. 17, 1411-1417 (2008).

47. Dorsam, B. \& Fahrer, J. The disulfide compound alpha-lipoic acid and its derivatives: A novel class of anticancer agents targeting mitochondria. Cancer Lett. 371, 12-19 (2016).

48. Harding, S. V., Rideout, T. C. \& Jones, P. J. H. Evidence for Using Alpha-Lipoic Acid in Reducing Lipoprotein and Inflammatory Related Atherosclerotic Risk. J. Diet. Suppl. 9, 116-127 (2012).

49. Kuhla, A., Ludwig, S. C., Kuhla, B., Münch, G. \& Vollmar, B. Advanced glycation end products are mitogenic signals and trigger cell cycle reentry of neurons in Alzheimer's disease brain. Neurobiol. Aging 36, 753-761 (2015).

50. Kim, M.-S. et al. Anti-obesity effects of alpha-lipoic acid mediated by suppression of hypothalamic AMP-activated protein kinase. Nat. Med. 10, 727-733 (2004).

51. Koh, E. H. et al. Effects of alpha-lipoic acid on body weight in obese subjects. Am. J. Med. 124, 85.e1-85.e8 (2011).

52. Midaoui, A. E. L. \& Champlain, J. De. Prevention of Hypertension, Insulin Resistance, and Oxidative Stress by alpha-Lipoic Acid. 303-307 (2002).

53. Zhang, Y. et al. Amelioration of lipid abnormalities by $\alpha$-lipoic acid through antioxidative and anti-inflammatory effects. Obesity (Silver Spring). 19, 1647-53 (2011).

54. Yang, R. li, Li, W., Shi, Y. H. \& Le, G. W. Lipoic acid prevents high-fat diet-induced dyslipidemia and oxidative stress: A microarray analysis. Nutrition 24, 582-588 (2008).

55. Butler, J. A., Hagen, T. M. \& Moreau, R. Lipoic acid improves hypertriglyceridemia by stimulating triacylglycerol clearance and downregulating liver triacylglycerol secretion. Arch. Biochem. Biophys. 485, 63-71 (2009).

56. Breithaupt-Grögler, K. et al. Dose-proportionality of oral thioctic acid - Coincidence of assessments via pooled plasma and individual data. Eur. J. Pharm. Sci. 8, 57-65 (1999).

57. Zehnpfennig, B., Wiriyasermkul, P., Carlson, D. a. \& Quick, M. Interaction of $\alpha$-Lipoic Acid with the Human $\mathrm{Na}^{+}$/Multivitamin Transporter (hSMVT). J. Biol. Chem. 290, 16372-16382 (2015).

58. Schupke, H. et al. New Metabolic Pathways of Alpha-Lipoic Acid 1 Abstract : 29, 855862 (2001).

59. Frank, L. L. Thiamin in Clinical Practice. J. Parenter. Enter. Nutr. (2015). doi:10.1177/0148607114565245

60. Hazell, A. S. \& Butterworth, R. F. Update of cell damage mechanisms in thiamine deficiency: Focus on oxidative stress, excitotoxicity and inflammation. Alcohol Alcohol. 44, 141-147 (2009). 
61. Xie, F. et al. Pharmacokinetic study of benfotiamine and the bioavailability assessment compared to thiamine hydrochloride. J. Clin. Pharmacol. 54, 688-695 (2014).

62. Alaei Shahmiri, F., Soares, M. J., Zhao, Y. \& Sherriff, J. High-dose thiamine supplementation improves glucose tolerance in hyperglycemic individuals: A randomized, double-blind cross-over trial. Eur. J. Nutr. 52, 1821-1824 (2013).

63. Alaei-Shahmiri, F., Soares, M. J., Zhao, Y. \& Sherriff, J. The impact of thiamine supplementation on blood pressure, serum lipids and C-reactive protein in individuals with hyperglycemia: a randomised, double-blind cross-over trial. Diabetes Metab. Syndr. Clin. Res. Rev. (2015). doi:10.1016/j.dsx.2015.04.014

64. Krol, E., Krejpcio, Z., Michalak, S., Wojciak, R. W. \& Bogdanski, P. Effects of combined dietary chromium(III) propionate complex and thiamine supplementation on insulin sensitivity, blood biochemical indices, and mineral levels in high-fructose-fed rats. Biol. Trace Elem. Res. 150, 350-359 (2012).

65. Al-attas, O. et al. Benefits of Six-month Thiamine Supplementation in Patients With and Without Diabetes Mellitus Type 2. Clin. Med. Insights Endocrinol. Diabetes. 1-7 (2014). doi:10.4137/CMED.S13573.RECEIVED

66. González-Ortiz, M., Martínez-Abundis, E., Robles-Cervantes, J. A., Ramírez-Ramírez, V. \& Ramos-Zavala, M. G. Effect of thiamine administration on metabolic profile, cytokines and inflammatory markers in drug-naïve patients with type 2 diabetes. Eur. J. Nutr. 50, 145-149 (2011).

67. Binns, S. COMBINING CURCUMIN AND ALPHA LIPOIC ACID TO TREAT CARDIOMETABOLIC SYNDROME. (2015).

68. Bangham, A. D., Standish, M. M. \& Watkins, J. C. Diffusion of univalent ions across the lamellae of swollen phospholipids. J. Mol. Biol. 13, 238-IN27 (1965).

69. Maradana, M. R., Thomas, R. \& O'Sullivan, B. J. Targeted delivery of curcumin for treating type 2 diabetes. Mol. Nutr. Food Res. 57, 1550-1556 (2013).

70. Kraft, J. C., Freeling, J. P., Wang, Z. \& Ho, R. J. Y. Emerging Research and Clinical Development Trends of Liposome and Lipid Nanoparticle Drug Delivery Systems. $J$. Pharm. Sci. 103, 29-52 (2014).

71. Davis, J. et al. Liposomal-encapsulated Ascorbic Acid : Influence on Vitamin C Bioavailability and Capacity to Protect Against Ischemia - Reperfusion Injury. Lib. Acad. 25-30 (2016). doi:10.4137/NMi.s39764.TYPE

72. Nielsen, S. et al. Body composition and resting energy expenditure in humans: role of fat, fat-free mass and extracellular fluid. Int. J. Obes. Relat. Metab. Disord. 24, 1153-1157 (2000).

73. McLaughlin, T. et al. Adipose Cell Size and Regional Fat Deposition as Predictors of Metabolic Response to Overfeeding in Insulin-Resistant and Insulin-Sensitive Humans. Diabetes 1-31 (2016).

74. Rosqvist, F. et al. Overfeeding polyunsaturated and saturated fat causes distinct effects on 
liver and visceral fat accumulation in humans. Diabetes 63, 2356-2368 (2014).

75. Bailey, R. L., Gahche, J. J., Miller, P. E., Thomas, P. R. \& Dwyer, J. T. Why US Adults Use Dietary Supplements. JAMA Intern. Med. 173, 355-61 (2013).

76. Nonrn, G. R. Supplements: A Complete guide to Safety. Consumers Union 20-33 (2004).

77. Cao, Y., Xu, R. X. \& Liu, Z. A high-throughput quantification method of curcuminoids and curcumin metabolites in human plasma via high-performance liquid chromatography/tandem mass spectrometry. J. Chromatogr. B Anal. Technol. Biomed. Life Sci. 949-950, 70-78 (2014).

78. Hermann, R., Mungo, J., Cnota, P. J. \& Ziegler, D. Enantiomer-selective pharmacokinetics, oral bioavailability, and sex effects of various alpha-lipoic acid dosage forms. Clin. Pharmacol. 6, 195-204 (2014).

79. Matsuda, M. \& DeFronzo, R. A. Insulin sensitivity indices obtained from oral glucose tolerance testing: Comparison with the euglycemic insulin clamp. Diabetes Care 22, 1462-1470 (1999).

80. Zhao, G. D., Sun, R., Ni, S. L. \& Xia, Q. Development and characterisation of a novel chitosan-coated antioxidant liposome containing both coenzyme Q10 and alpha-lipoic acid. J. Microencapsul. 32, 157-165 (2015).

81. Fernandez-Galilea, M. et al. Alpha-Lipoic acid treatment increases mitochondrial biogenesis and promotes beige adipose features in subcutaneous adipocytes from overweight/obese subjects. Biochim. Biophys. Acta - Mol. Cell Biol. Lipids 1851, 273-281 (2015).

82. Jäger, R. et al. Comparative absorption of curcumin formulations. Nutr. J. 13, 11 (2014).

83. Ashutosh, P. et al. Curcumin Glucuronides: Assessing the Proliferative Activity against Human Cell Lines. Bioorg Med Chem. 100, 435-439 (2014).

84. Choudhury, A. K., Raja, S., Mahapatra, S., Nagabhushanam, K. \& Majeed, M. Synthesis and Evaluation of the Anti-Oxidant Capacity of Curcumin Glucuronides, the Major Curcumin Metabolites. Antioxidants (Basel, Switzerland) 4, 750-67 (2015).

85. Seyssel, K. et al. Regulation of Energy Metabolism and Mitochondrial Function in Skeletal Muscle During Lipid Overfeeding in Healthy Men. J. Clin. Endocrinol. Metab. 99, E1254-E1262 (2014).

86. Cahill, F. et al. Short-Term Overfeeding Increases Circulating Adiponectin Independent of Obesity Status. PLoS One 8, 1-8 (2013).

87. Laugerette, F. et al. Overfeeding increases postprandial endotoxemia in men: Inflammatory outcome may depend on LPS transporters LBP and sCD14. Mol. Nutr. Food Res. 58, 1513-1518 (2014).

88. Palmer, B. F. \& Clegg, D. J. The sexual dimorphism of obesity. Mol. Cell. Endocrinol. 402, 113-119 (2015).

89. Kelley, D. E. et al. Subdivisions of subcutaneous abdominal adipose tissue and insulin 
resistance Subdivisions of subcutaneous abdominal adipose tissue and insulin resistance. 941-948 (2011).

90. Nicol, C. J., Adachi, M., Akiyama, T. E. \& Gonzalez, F. J. PPAR-gamma in endothelial cells influences high fat diet-induced hypertension. Am. J. Hypertens. 18, 549-556 (2005).

91. Chaar, L. J., Coelho, A., Silva, N. M., Festuccia, W. L. \& Antunes, V. R. High-fat dietinduced hypertension and autonomic imbalance are associated with an upregulation of CART in the dorsomedial hypothalamus of mice. Physiol. Rep. 4, 1-15 (2016).

92. Stirban, a., Pop, a. \& Tschoepe, D. A randomized, double-blind, crossover, placebocontrolled trial of 6 weeks benfotiamine treatment on postprandial vascular function and variables of autonomic nerve function in Type 2 diabetes. Diabet. Med. 30, 1204-1208 (2013).

93. McLaren, L. et al. Population-level interventions in government jurisdictions for dietary sodium reduction. Cochrane Database Syst. Rev. (2012). doi:10.1002/14651858.CD010166

94. Pickering, T. G. et al. Recommendations for blood pressure measurement in humans and experimental animals: part 1: blood pressure measurement in humans: a statement for professionals from the Subcommittee of Professional and Public Education of the American Heart Association Cou. Circulation 111, 697-716 (2005).

95. Vasan, R. S., Larson, M. G., Leip, E. P., Kannel, W. B. \& Levy, D. Assessment of frequency of progression to hypertension in non-hypertensive participants in the Framingham Heart Study: A cohort study. Lancet 358, 1682-1686 (2001).

96. Hulston, C. J., Churnside, A. a \& Venables, M. C. Probiotic supplementation prevents high-fat, overfeeding-induced insulin resistance in human subjects. Br. J. Nutr. 1-7 (2015). doi:10.1017/S0007114514004097

97. Wiedemann, M. S. F., Wueest, S., Item, F., Schoenle, E. J. \& Konrad, D. Adipose tissue inflammation contributes to short-term high-fat diet-induced hepatic insulin resistance. Am. J. Physiol. Endocrinol. Metab. 305, E388-95 (2013).

98. Dirks, M. L. et al. One week of bed rest leads to substantial muscle atrophy and induces whole-body insulin resistance in the absence of skeletal muscle lipid accumulation. Diabetes 65, db151661 (2016).

99. Snook, L. A. et al. Prior Exercise Training Blunts Short Term High Fat Diet Induced Weight Gain. Am. J. Physiol. - Regul. Integr. Comp. Physiol. ajpregu.00072.2016 (2016). doi:10.1152/ajpregu.00072.2016

100. Anderson, A. S. et al. Early skeletal muscle adaptations to short-term high-fat diet in humans before changes in insulin sensitivity. Obesity 23, 720-724 (2015).

101. Helander, E. E. \& Wansink, B. Weight Gain over Holidays in Three Countries. N Engl J Med 374, 62-72 (2016).

102. Swinburn, B. A. et al. Estimating the changes in energy flux that characterize the rise in. Am. J. Clin. Nutr. 1723-8 (2009). doi:10.3945/ajcn.2008.27061.1 


\title{
APPENDIX
}

Consent Form

\section{Consent to Participate in a Research Study Colorado State University}

TITLE OF STUDY: Does Liposomal Encapsulated Curcumin/Benfotiamine/Alphalipoic-acid Provide Superior Resistance to High-Fat, Over-Feeding Induced Insulin Resistance?

\author{
PRINCIPAL INVESTIGATOR: \\ Christopher Bell, Ph.D. \\ Department of Health and Exercise Science \\ Colorado State University \\ Fort Collins \\ CO 80523-1582
}

Telephone: 970-491-3495

Fax: 970-491-0445

Email:physiology@cahs.colostate.edu

\section{WHY AM I BEING INVITED TO TAKE PART IN THIS RESEARCH?}

You are an adult man or woman aged between 18 and 30 years. You are not pregnant. Your fasting blood glucose is $<100 \mathrm{mg} / \mathrm{dL}$. Your body mass index (BMI) is less than 30 $\mathrm{kg} / \mathrm{m}^{2}$. You regularly exercise at least 2-3 times per week. You own a cell phone, or other portable electronic device, capable of taking and sending photographs.

\section{WHO IS DOING THE STUDY?}

Christopher Bell, Ph.D., an associate professor in the Department of Health and Exercise Science at Colorado State University will perform this research. Colleagues at Colorado State University, appropriately qualified staff, and trained graduate and undergraduate students will assist Dr. Bell. The CSU Agricultural Experiment Station is funding the study. Empirical Labs, a Fort Collins based company, is providing and preparing the Curcumin, Benfotiamine and Alpha-lipoic-acid.

\section{WHAT IS THE PURPOSE OF THIS STUDY?}

The commercially available dietary supplements Curcumin, Benfotiamine and Alphalipoic-acid may help prevent obesity-related cardiovascular and metabolic diseases. However, the ability of the body to absorb and use these supplements is quite low. This study has two purposes: 1 ) to determine if the concentration of the supplements in the blood can be increased when given in a liposome. A liposome is a microscopic hollow bubble or parcel that can be filled with different foods or medications. Liposomes are not new, not risky and have been used as a way to give drugs from many years. We want to know if putting Curcumin, Benfotiamine and Alpha-lipoic-acid inside a liposome 
will result in more Curcumin, Benfotiamine and Alpha-lipoic-acid in the blood. 2) Not exercising, and over-eating a diet that is high in fat, can decrease your ability to control blood sugar. We want to know if Curcumin, Benfotiamine and Alpha-lipoic-acid will prevent the decrease in blood sugar control that accompanies 1 week of over-eating.

\section{WHERE IS THE STUDY GOING TO TAKE PLACE AND HOW LONG WILL IT LAST?}

All of the procedures will take place at Colorado State University (Fort Collins main campus) in either the Human Performance Clinical/Research laboratory (HPCRL) in the Department of Health \& Exercise Science (Moby Complex), or in the Rams Horn Dining Center.

This whole research project will take place over a period of approximately 2 years. You will be asked to be involved for approximately 4 weeks. The total time of your participation will be approximately 21 hours spread over 4 weeks including 6 visits to our laboratory and 7 days eating 3 meals per day at the on-campus dining facility.

\section{WHAT WILL I BE ASKED TO DO?}

Overview:

You will be randomized into one of three groups: a group that receives a placebo (something that has no effect), a group that receives curcumin, benfotiamine and alphalipoic-acid, or a group that receives curcumin, benfotiamine and alpha-lipoic-acid "packed" inside liposomes. For 28 days you will be asked to swallow/drink either: a placebo (something that has no effect), curcumin, benfotiamine and alpha-lipoic-acid, or curcumin, benfotiamine and alpha-lipoic-acid "packed" inside liposomes. During the last 7 days you will stop exercising and eat more food than usual. Your ability to control blood sugar will be measured three times (in the beginning, and before/after overeating). We will also sample some of your fat. 


\begin{tabular}{|l|l|l|l|}
\hline Visit & Day & Activity & Duration \\
\hline 1 & & Screening / Activity and Diet Questionnaires & 1.5 Hours \\
\hline 2 & & RMR & 1 Hour \\
\hline 3 & -1 & OGTT / Stool Sample & 2.5 Hours \\
\hline & $0-28$ & Daily ingestion of supplement or placebo & \\
\hline 4 & & $\begin{array}{l}\text { Tour of Rams Horn Dining Facility } \\
\text { Diet Plan }\end{array}$ & 1 Hour \\
\hline 5 & 21 & OGTT / DEXA / Fat Sample / Stool Sample & 3 Hours \\
\hline & $22-28$ & 3 meals per day in Rams Horn Dining Facility & \\
\hline 6 & 29 & OGTT / DEXA / Fat Sample / Stool Sample & 3 Hours \\
\hline
\end{tabular}

RMR: Resting metabolic rate. OGTT: Oral Glucose Tolerance Test. DEXA: Dual Energy X-Ray Absorptiometry

Visit 1 will comprise a screening visit. Visit 2 will involve the measurement of the number of calories you burn at rest and completion of diet and activity questionnaires. Visit 3 will involve a test of your ability to control blood sugar. Visit 4 will comprise a tour of the Rams Horn Dining Facility where you will be given instructions on the diet you will be asked to follow for the 7 days. Visit 5 will involve a test of your ability to control blood sugar, measurement of your body composition, and a fat sample. Day 22 -28 will require you to eat 3 meals per day at the Rams Horn Dining Facility from a pre-specified menu. Visit 6 will involve a test of your ability to control blood sugar, measurement of your body composition, and a fat sample.

\section{Supplements}

The dietary supplements will be given to you in a liquid (a beverage) to be swallowed two times per day. You will not know the contents of the liquid to which you have been assigned until the end of the study. The liquid supplements will either contain a placebo (something that has no effect) or the following ingredients such that the daily dose is:

Curcumin $-2.0 \mathrm{~g}$

Benfotiamine $-500 \mathrm{mg}$

Alpha-lipoic-acid - $500 \mathrm{mg}$

Curcumin is a natural ingredient in a spice usually found in Indian foods (e.g. curry). The spice is turmeric. 
Benfotiamine is almost exactly the same as vitamin B1.

Alpha-Lipoic Acid is a very common ingredient in multivitamin formulas. It is also found in some types of meat (e.g. heart, kidney, and liver) and in small amounts in some fruits and vegetables.

To make the liquids taste better, you will be provided with juice. You will be shown how to dilute the liquids in the juice. You will swallow the liquids every morning and every evening.

Visit 1 - Screening Visit $~ 1.5$ Hours

The first visit to the HPCRL will be a screening visit. During this visit we will make sure that participation in this study is right for you.

\section{Medical Questionnaire}

You will be asked to answer several pages of questions related to your health, any illness you may have or have had, and medications and/or supplements you use or have used in the past. If you are pregnant you will not be able to participate in the study.

\section{Physical Activity and Dietary Questionnaires}

You will be asked to answer several pages of questions related to your current and past physical activity level, and questions related to your normal eating habits, including any dietary restrictions such as food allergies or intolerances.

\section{Body Composition}

We will measure the different compositions of your body including how much fat mass, non-fat mass and total bone density total, as well as where fat mass is concentrated on your body. We will be using a test called dual energy $x$-ray absorptiometry (DEXA). The DEXA test requires you to lie quietly on a padded table while a small probe gives off low-level $\mathrm{x}$-rays and sends them over your entire body. This test gives very accurate measurements of your body fat and bone mineral density. We will verify that you are not currently pregnant by conducting a pregnancy test using a urine sample. We will measure your height and weight using a physician's scale. (Duration: 15 minutes)

\section{Visit 2 - Resting Metabolic Rate - 1 Hour}

Early during one morning, at the start of your day, we will measure how your metabolism works (how many calories you burn) while you are resting. You will be asked to lie down while breathing under a clear plastic bubble (hood) for approximately 45 minutes. You will be asked not to eat or drink anything other than water during the 12-hours before this test. 


\section{Visit 3 - Blood Sugar Test -2.5 Hours}

You will be required to refrain from eating for 12-hours and not exercise for 48 hours before this visit.

You will also be asked to provide a stool sample. You will be provided with a container and instructions as to how to collect your stool.

We will place a hollow plastic tube (a venous catheter) into a vein in your arm or hand. The tube will remain in your vein for approximately 2 hours. We will sample a very small amount of blood ( $160 \mathrm{ml}$ or 11 teaspoons) throughout the duration of each visit.

You will be asked to drink water (300 $\mathrm{ml}$ or $\sim 10 \mathrm{oz}$ ) in approximately 5 minutes. A small amount of sugar ( $75 \mathrm{~g}$ of glucose) will have been added to the water. This will make it taste sweeter and also increase your blood sugar.

After drinking the water you will sit/lie quietly for 2 hours. You will be able to read and/or watch TV and/or listen to music. We will collect blood from you over the 2 hours. Your blood will be analyzed for concentrations of sugar (glucose), insulin (something that helps control blood sugar), concentrations of benfotiamine, alpha-lipoic-acid and curcumin, and other things that might help/hinder your metabolism

\section{Visit 4 - Tour of Rams Horn Dining Facility \& Diet Plan 1 hour}

You will meet with a Registered Dietitian Nutritionist (RDN) who will explain the high-fat overfeeding diet that you will be eating for 7 days. The RDN will give you a short tour of the on-campus dining facility where you will be eating for 7 days, 3 meals each day, along with instructions on gaining access to the facility and hours of operation.

You will also receive a specific dietary plan to follow for that 7 day period outlining the specific foods and portions for each of the 3 meals. You will be asked to take pictures of each of your meals for these 7 days with your personal cell phone/camera and send these pictures to the RDN. This will ensure you are correctly following the diet plan.

\section{Visits 5 \& 6 - Blood Sugar Test, DEXA \& Fat Sampling - 3 Hours}

These visits are identical and will occur the day before and the day after your 7-days of over-eating in the Rams Horn Dining facility.

You will be required to refrain from eating for 12-hours before each visit. You will be asked not to exercise for 48 hours before visit 5 and for 7 days before visit 6 .

You will also be asked to provide a stool sample. You will be provided with a container and instructions as to how to collect your stool.

We will place a hollow plastic tube (a venous catheter) into a vein in your arm or hand. The tube will remain in your vein for approximately 2 hours. We will sample a very small amount of blood ( $160 \mathrm{ml}$ or 11 teaspoons) throughout the duration of each visit. 
You will be asked to drink water (300 $\mathrm{ml}$ or $\sim 10 \mathrm{oz}$ ) in approximately 5 minutes. A small amount of sugar ( $75 \mathrm{~g}$ of glucose) will have been added to the water. This will make it taste sweeter and also increase your blood sugar.

After drinking the water you will sit/lie quietly for 2 hours. You will be able to read and/or watch TV and/or listen to music. We will collect blood from you over the 2 hours. Your blood will be analyzed for concentrations of sugar (glucose), insulin (something that helps control blood sugar), concentrations of benfotiamine, alpha-lipoic-acid and curcumin, and other things that might help/hinder your metabolism.

\section{Body Composition}

We will repeat the DEXA measurement described on a previous page.

\section{Fat Sampling}

This procedure is also known as a fat biopsy or liposuction. Fat is a very important tissue for metabolism and blood sugar control. We wish to determine if fat will change in response to curcumin, benfotiamine and alpha-lipoic-acid, and/or overfeeding.

A small $(2-5 \mathrm{~g} /$ less than $1 \mathrm{oz})$ amount of fat will be sampled from a tiny $(0.5 \mathrm{~cm} /$ less than $1 / 4$ of an inch) incision made under local anesthesia (numbing medication). The most commonly sampled sites are the hip, mid-thigh and stomach (abdominal) regions. The average American adult has roughly $18 \mathrm{~kg}$ of adipose tissue (fat), thus the size of the sample we will be taking represents a tiny fraction (less than $0.1 \%$ ) of your total fat. Appropriately trained personnel will perform this procedure. 
ARE THERE REASONS WHY I SHOULD NOT TAKE PART IN THIS STUDY? You will not be allowed to participate in these studies for any of the following reasons:

1) You are pregnant or you are a nursing mother.

2) You regularly use any prescription medications that may affect blood sugar.

3) You are younger than 18 or older than 30 years.

4) Your body mass index (an expression of weight divided by height) is greater than 30 $\mathrm{kg} / \mathrm{m}^{2}$.

5) You are currently taking or have regularly taken in the past, medication(s) or supplement(s) that influence metabolism, oxidative stress and/or inflammation.

6) You are allergic to lidocaine (numbing medication often used by a dentist).

7) You are unwilling to stop exercising for 2-9 days, as required by the protocol.

8) You are unwilling to eat more food than usual, every day, for 7-days.

\section{WHAT ARE THE POSSIBLE RISKS AND DISCOMFORTS?}

It is not possible to identify all potential risks in research procedures, but the researcher(s) have taken reasonable safeguards to minimize any known and potential, but unknown, risks. The Human Performance Clinical Research Laboratory has emergency supplies including a medicine trolley equipped with heart machines and supplemental oxygen. The investigator has a great deal of experience with all of the procedures. Some of the procedures for which you are being asked to volunteer have a number of associated risks:

\section{Body Composition}

The risks associated with the DEXA are very low. The maximum radiation dose you will receive in this study is less than $1 / 1000^{\text {th }}$ of the federal and state occupational whole body dose limit allowed to radiation workers (5,000 mrem). Put another way, the maximum dose from any scan we utilize with this DEXA ranges from $1.2 \mathrm{mrem}$ (Whole body scan) to 12.2 mrem (for several of the regional scans, such as lumbar, femur, and forearm scans). The average annual background radiation you already receive is at least $620 \mathrm{mrem} / \mathrm{year}$. The more radiation you receive over the course of your life, the more the risk increases of developing a fatal cancer or inducing changes in genes. The radiation in this scan is not expected to significantly increase these risks, but the exact increase in such risks is not known. There are no discomforts associated with this procedure.

\section{Blood Collection}

When the needle goes into a vein, it may hurt for a short period of time (a few seconds). Also there may be minor discomfort of having the needle/plastic tube taped to your arm. In about 1 in 10 cases, a small amount of bleeding will occur under the skin that will cause a bruise. The risk of forming a blood clot in the vein is about 1 in 100, and the risk of significant blood loss is 1 in 1,000. Additionally, there is a risk that you may faint while having blood collected or having the catheter inserted in your vein.

\section{Blood Sugar (Glucose Tolerance) Test}

The risks outlined above with the blood collection portion also apply to this test as we will be collecting blood samples over the course of the 2 hour period. You will also be 
asked to fast before starting the test and then ingest a very concentrated "sugar" solution that can cause some discomfort. Some participants may feel nauseated, sweaty or light-headed after they drink the solution. There are no serious side effects associated with this test.

\section{Fat Sample}

The risk of an allergic reaction to lidocaine (numbing medication) and lidocaine toxicity is extremely low ( 0 in the more than 2000 cases witnessed by both CSU and University of Colorado investigators). There is a small risk of infection (less than $0.4 \%$ ) at the site of incision. There is a small risk of the incision reopening/bleeding after leaving the lab. There is a small risk of pain at the biopsy site during and/or after the procedure. You may develop a temporary bruise at the biopsy site. There is a small risk of more significant bleeding under the skin (hematoma). You will have a small scar at the incision site. The rate and degree of healing varies considerably, but it is expected that scars will be difficult to see within 6-12 months after the procedure.

Over-Eating For 7 Days While Not Exercising You are likely to gain weight (approximately $1 \mathrm{~kg} / 2 \mathrm{lbs}$ ). Your ability to control your blood sugar is likely to decrease. You may feel full (satiated) after each meal. You may begin to feel grumpy (irritable) because you are not exercising. You may experience a decrease in fitness (stamina/strength/flexibility/etc.) The effects of 7 days of overfeeding while not exercising are temporary. Your weight and blood sugar will return to normal within 7-10 days once you return to your normal diet and usual exercise activities. Should you wish, we will provide diet and exercise advice to help you return to your original weight.

Risks of Curcumin, benfotiamine and alpha-lipoic-acid Curcumin, benfotiamine and alpha-lipoic-acid are considered safe and usually do not cause significant side effects when doses similar to those in the present study are swallowed. However, some side effects are possible; these may include: worsening of gallbladder problems, a skin rash, and stomach upset, which may make gastroesophageal reflux disease (GERD) worse. 


\section{FUTURE USE OF BLOOD, FAT OR STOOL SAMPLES}

It is possible that we may want to use any leftover blood, fat or stool for future research not described in this consent form. We will keep private all research records that identify you (to the extent allowed by law) for both current and future use (please refer to the section, "WHO WILL SEE THE INFORMATION THAT I GIVE" for more information regarding privacy). Future research will pertain to physiological function. Choose only one of the following:

I give permission for the use of my blood, stool and/or fat tissue collected as part of the current study only.

(your initials)

I give permission for the use of my blood, stool and/or fat tissue for the current study as well as for future studies.

(your initials)

\section{ARE THERE ANY BENEFITS FROM TAKING PART IN THIS STUDY?}

There are no direct benefits in participating, however you will receive a copy of your results and information pertinent to your body composition (i.e. height and weight), and metabolic risk factors. For example, in blood we will measure concentrations of glucose. You will be provided with a copy of your DEXA scan; you may wish to have this interpreted by a medically qualified professional. Finally, this study has the potential to identify a dietary supplement that may benefit society and help prevent obesity-related chronic diseases.

\section{DO I HAVE TO TAKE PART IN THE STUDY?}

Your participation in this research is voluntary. If you decide to participate in the study, you may withdraw your consent and stop participating at any time without penalty or loss of benefits to which you are otherwise entitled.

\section{WHAT WILL IT COST ME TO PARTICIPATE?}

Other than transport to and from the lab and on-campus dining facilities, your participation should incur no costs.

\section{WHO WILL SEE THE INFORMATION THAT I GIVE?}

We will keep private all research records that identify you, to the extent allowed by law.

Your information will be combined with information from other people taking part in the study. When we write about the study to share with other researchers, we will write about the combined information we have gathered. You will not be identified in these written materials. We may publish the results of this study; however, we will keep your name and other identifying information private. We may be asked to share the research files with the CSU Institutional Review Board ethics committee for auditing purposes. 
Your identity/record of receiving compensation (NOT your data) may be made available to CSU officials for financial audits.

\section{CAN MY TAKING PART IN THE STUDY END EARLY?}

Your participation in the study could end if you become pregnant, or if you miss any of the scheduled appointments.

WILL I RECEIVE ANY COMPENSATION FOR TAKING PART IN THIS STUDY? If you complete the entire study you will receive $\$ 300$. This payment will be prorated as follows: You will not receive compensation if you only complete screening visit. If you complete visits 1-2 you will receive $\$ 15$. If you complete visits 1-3 you will receive $\$ 45$. If you complete visits 1-5 you will receive $\$ 100$.

Should your participation in the study end early, you will still receive feedback pertaining to your health and fitness.

WHAT HAPPENS IF I AM INJURED BECAUSE OF THE RESEARCH? We will arrange to get you medical care if you have an injury that is caused by this research. However, you or your insurance company will have to pay for that care. The Colorado Governmental Immunity Act determines and may limit Colorado State University's legal responsibility if an injury happens because of this study. Claims against the University must be filed with Colorado State University within 180 days of the injury.

\section{WHAT IF I HAVE QUESTIONS?}

Before you decide whether to accept this invitation to take part in the study, please ask any questions that might come to mind now. Later, if you have questions about the study, you can contact the investigator, Christopher Bell at physiology@cahs.colostate.edu or 970-491-3495. If you have any questions about your rights as a volunteer in this research, contact the CSU IRB at:

RICRO IRB@mail.colostate.edu; 970-491-1553. We will give you a copy of this consent form to take with you. 


\section{WHAT ELSE DO I NEED TO KNOW?}

Your signature acknowledges that you have read the information stated and willingly sign this consent form. Your signature also acknowledges that you have received, on the date signed, a copy of this document containing 11 pages.

$\overline{\text { Signature of person agreeing to take part in the study }}$ Date

Printed name of person agreeing to take part in the study Time of Day

Name of person providing information to participant

Date

Signature of Research Staff 